\title{
Tool for Observing Play Outdoors (TOPO): A New Typology for Capturing Children's Play Behaviors in Outdoor Environments
}

\author{
Janet Loebach ${ }^{1, *(D)}$ and Adina Cox ${ }^{2}$ (D) \\ 1 Design and Environmental Analysis, Cornell University, Ithaca, NY 14850, USA \\ 2 Landscape Architecture, University of Kentucky, Lexington, KY 40506, USA; Adina.Cox@uky.edu \\ * Correspondence: j.loebach@cornell.edu
}

Received: 8 July 2020; Accepted: 26 July 2020; Published: 4 August 2020

check for updates

\begin{abstract}
Engagement in play has been definitively linked to the healthy development of children across physical, social, cognitive, and emotional domains. The enriched nature of high-quality outdoor play environments can afford a greater diversity of opportunities for play than indoor settings. To more effectively design outdoor play settings, we must better understand how the physical environment supports, or hinders, the different types of play which suit children's needs and interests. However, play typologies or observation tools available to date do not adequately capture the unique characteristics of outdoor play. This paper outlines the development and testing of the Tool for Observing Play Outdoors (TOPO), a new typology of outdoor play, as well as a systematic field observational protocol which can be used to effectively depict children's behaviors in outdoor spaces, as well as evaluate the play environment itself. The tool can be deployed in either a collapsed or expanded form to serve the needs of a wide range of studies and environments. This new tool represents a significant advance in the ability to fully and effectively study and plan outdoor play environments to provide more diverse, high-quality play settings that will support the healthy development of children across the spectrum.
\end{abstract}

Keywords: outdoor play; play types; typology; play environments; children's behavior; play spaces; children's development; observation tool; nature play

\section{The Developmental Drive for Play}

Children's play activities, so long considered to be largely superfluous and aimless [1], or as a way for children to let off steam between formal learning activities, have been definitively linked to the health and development of children [1,2]. Several reviews of the research evidence conducted by the American Academy of Pediatrics (APA) clearly demonstrate the "critical importance of play in facilitating parent engagement; promoting safe, stable and nurturing relationships; encouraging the development of numerous competencies, including executive function skills; and improving life course trajectories" [3-5] (p. 2). Through play, children learn how to engage successfully in their socio-cultural environments, creating and trying out experiences in safe simulations which do not threaten their physical or emotional well-being $[2,3]$. The impact of play is cumulative and iterative; skills and knowledge accrue during play, nurturing both short- and long-term effects on children's development [1,2]. Brown claims that play seems to be "so important to our development and survival that the impulse to play has become a biological drive ... the impulse to play is internally generated" [2] (p. 42). Children are inherently drawn to the low-risk scenarios of play in order to learn, grow, adapt, and thrive.

Neuroscience studies in recent years have also tied play in childhood to the development and proper functioning of the brain. In a recent APA review, Yogman et al. concluded from this evidence 
that "play is not frivolous, it is brain building" [3] (p. 5). Animal play researchers who have extensively studied the impact of play on brain development propose that during play, the brain is actually "making sense of itself through simulation and testing. Play activity is actually helping to sculpt the brain" [2] (p. 34). This helps to explain why play is most prevalent during childhood, the most significant period of brain development [2,3].

Neuroscience studies have also demonstrated that when children play, all areas of the brain "light up", leading to adaptive and prosocial changes at each of the molecular, cellular, and behavioral levels, reinforcing that play activities can simultaneously foster development and learning across all domains-physical, social, cognitive, and emotional [2,3]. These insights suggest we should guard against an approach to play which creates artificial silos between developmental domains, associating certain types of play with a single area of development, but rather understanding play as activities which integrate development across domains. This research on the integrative impact of play on development also reminds us to acknowledge the cognitive and socioemotional aspects of playful activities; a common perception of play—particularly outdoor play-is that it is primarily physical and highly active in nature, yet quieter and more reflective activities are prevalent forms of play and important sources of learning and psychological development. One key to producing play-rich environments for children is understanding how environments can facilitate all forms of developmentally supportive activities and interactions.

\section{Importance of Supportive Outdoor Play Environments}

The forms of play in which children engage are incredibly diverse, and highly tied to this evolving developmental drive and the skills that the child has previously mastered [6,7]. The great benefit that outdoor play can offer is a greater diversity of opportunities for rich, integrated play. The more varied and less structured nature of outdoor play environments, and the fewer constraints they place on the type and range of children's play activities, typically provide a more "enriched environment" than indoor settings, and are more likely to stimulate creativity and problem-solving, support children's physical development, and facilitate learning [8] (p. 48). Reviewing decades of studies, Frost et al. [9] (p. 292) concluded that "children play differently outdoors than they play indoors"; play and language tends to be more complex, more dramatic play is observed, and children engage in more physically active play. Studies have demonstrated that environments which support diverse types of play will see not only a greater overall proportion of children engaged, but for longer periods of time [6]. Outdoor environments which also include substantial natural elements and materials can offer even more play opportunities; nature-based play spaces have been shown to foster more varied and complex play than traditional outdoor playgrounds [10-12]. A growing evidence base suggests nature-rich play spaces may also improve children's physical, emotional, and social health by fostering motor skills development [13], reducing stress [14,15], mitigating symptoms of ADD/ADHD [16], and decreasing prevalence of allergies [17].

While child development specialists, early educators, and now neuroscientists have clearly established play as critical to human development, and largely debunked the notion that play is less important to development and learning than more formal educational activities [1,9], widespread reductions in school recess time in the U.S. and in free time for outdoor play for children in many developed countries suggest that it remains critical that we establish a clear link between play in rich, varied outdoor environments and children's full development. Part of this effort entails generating a larger evidence base linking features and conditions of outdoor play environments to children's healthy development.

\section{Rationale for the Development of a New Outdoor Play Observation Tool}

The study of outdoor play is important for understanding how we can more effectively design play environments that support children's development and interests. Understanding how the physical environment supports, or hinders, different types of play can facilitate the design and programming 
of outdoor spaces which better suit children's play needs and interests. However, play typologies or observation tools available to date do not adequately capture the unique characteristics of outdoor play to support effective evaluation of children's activities or the outdoor play environment itself.

Many studies to date have utilized a play typology to help categorize children's play behavior in relation to an outdoor environment [13,14,18-20]. These studies often use a previously developed play type scale (or an adaption thereof), the most prevalent of which are Frost's Play Observation Form [21], Hughes' Playworker's Taxonomy of Play Types [22,23], and Rubin's Play Observation Scale [24-26]. However, each of these typologies pose difficulties for the categorization of play types observed in outdoor settings.

In his 1992 book Play and Playscapes [21], Frost, a well-known play researcher, synthesizes play types proposed previously by psychologists Buhler (1937), Piaget (1962), and Smilansky (1968) to identify four types of "cognitive" play which were considered to emerge in parallel with a child's intellectual development, outlining an evolutionary set of play types (See Table 1). Beginning with the earliest form of functional play, the simple, repetitive actions observed within the first two years of life, Frost's categories reflect the types of play that emerge as a child develops cognitively. Functional play is then supplemented with the more goal-oriented activities termed construction play, followed by the pretend games and make-believe behavior of symbolic play, eventually culminating in games with rules which were meant to reflect the highest level of cognitive development, that is, play with other children that is bound and regulated by a set of agreed-upon rules [21]. Frost acknowledges that the earlier forms of play do not disappear from children's play activities as they progress to more mature forms, but also reinforces the notion that these types of play emerge in a fairly fixed and linear sequence, and implies that symbolic and rule-bound play are more desirable for being more cognitively advanced forms of play. To aid in the categorization of play behaviors during observations of children, Frost developed the Play Observation Form, which allows observers to code behaviors as either a form of cognitive play, other play, or non-play (See Table 1). The form privileges the three types of cognitive play outlined by Piaget [27] - functional, dramatic, and organized games—which are then cross-referenced with three levels of social play based on the work of Parten [28] — solitary, parallel, and group play. While Frost proposes most behaviors will be captured within this cognitive-social play matrix, the form does allow the observer to acknowledge "other" forms of play as well-exploratory, constructive, rough and tumble, and chase games. Behaviors such as unoccupied, onlooker, transition, and aggression were identified as non-play. Frost's Play Observation Form was largely intended to study the play behaviors of children under the age of 5 years in indoor settings, such as preschools or childcare facilities. While his proposed typology may still serve to help identify a child's level of cognitive development through play, and can perhaps be utilized for categorizing outdoor play types at a very high level, with only three main categories of play and without clear integration of the "other" play categories it is not broad or defined enough to effectively capture the diversity of rich play activities children engage in outdoors. 
Table 1. Play typology comparison.

\begin{tabular}{|c|c|c|c|c|c|c|}
\hline Parten (1932) & K. Buhler (1937) & Piaget (1962) & Smilansky (1968) & Frost (1992) & Hughes $(1996 ; 2002)$ & Rubin $(2001 ; 2008)$ \\
\hline $\begin{array}{l}\text { Social play } \\
\text { Unoccupied behavior } \\
\text { Onlooker behavior } \\
\text { Solitary play } \\
\text { Parallel play } \\
\text { Associative play } \\
\text { Cooperative play }\end{array}$ & $\begin{array}{l}\text { Cognitive play } \\
\text { Functional games } \\
\text { Construction games } \\
\text { Make-believe games } \\
\text { Collective games }\end{array}$ & $\begin{array}{l}\text { Cognitive play } \\
\text { Practice games } \\
\text { Symbolic games } \\
\text { Games with rules }\end{array}$ & $\begin{array}{l}\text { Cognitive play } \\
\text { Functional games } \\
\text { Construction play } \\
\text { Dramatic play } \\
\text { Games with rules }\end{array}$ & $\begin{array}{l}\text { Cognitive play } \\
\text { Functional play } \\
\text { Dramatic play } \\
\text { Organized games } \\
\text { Social play } \\
\text { Solitary } \\
\text { Parallel } \\
\text { Group } \\
\text { Other } \\
\text { Exploratory } \\
\text { Constructive } \\
\text { Rough and tumble } \\
\text { Chase games } \\
\text { Non-Play } \\
\text { Unoccupied } \\
\text { Onlooker } \\
\text { Transition } \\
\text { Aggression }\end{array}$ & $\begin{array}{l}\text { Play types } \\
\text { Symbolic play } \\
\text { Rough and tumble play } \\
\text { Socio-dramatic play } \\
\text { Social play } \\
\text { Creative play } \\
\text { Communication play } \\
\text { Dramatic play } \\
\text { Locomotor play } \\
\text { Deep play } \\
\text { Exploratory play } \\
\text { Fantasy play } \\
\text { Imaginative play } \\
\text { Mastery play } \\
\text { Object play } \\
\text { Role play } \\
\text { Recapitulative play }\end{array}$ & $\begin{array}{l}\text { Cognitive } \\
\text { Functional play } \\
\text { Constructive play } \\
\text { Exploration * } \\
\text { Dramatic play } \\
\text { Games with rules } \\
\text { Occupied } \\
\text { Social play } \\
\text { Solitary } \\
\text { Parallel } \\
\text { Group } \\
\text { Non-play } \\
\text { Unoccupied behavior } \\
\text { Onlooker behavior } \\
\text { Transition } \\
\text { Active conversation } \\
\text { Uncodable behavior } \\
\text { Out of room } \\
\text { Adult interaction/conversation } \\
\text { Double coded behaviors } \\
\text { Aggression } \\
\text { Rough and Tumble } \\
\text { Hovering } \\
\text { Anxious behaviors }\end{array}$ \\
\hline
\end{tabular}


Hughes' taxonomy of play types was developed primarily as a guide for playworkers, "to enable those who worked with children to call similar playful routines by the same names" [29] (p. 97). Hughes identifies 16 different types of play (See Table 1), from symbolic play to rough and tumble play, communication play, deep play, and recapitulative play as a way of helping playworkers to identify and facilitate a broad range of play activities, and to help them understand what children gain from engaging in different types of play $[22,23]$. While the taxonomy has proved useful as a framework for playworkers and early-year educators, there are several factors which make it difficult to use as a framework for an observational tool. The largest hurdle is that the types of play outlined often overlap in their descriptions, or their distinctions are not necessarily observable. For example, Hughes outlines several play types which all describe activities where a child explores or takes on a pretend role or persona as part of an imaginary play scenario-role play, socio-dramatic play, dramatic play, and fantasy play. Each type of play allows the child to experiment with different ways of being, and to test their own capacity for taking on different roles or tasks, often utilizing elements in their environment as pretend props. However, these four play types are not necessarily mutually exclusive, and the distinctions between them are often not clear or robust enough to allow for consistent categorization by an observer. For example, a child observed pretending to be a bus driver "driving" a cardboard box "bus" could conceivably fall under more than one of these categories. In addition, some categories, while describing play experiences that can be extremely valuable for children, represent a set of behaviors or learnings that are not necessarily observable to another person. For example, deep play, which involves encounters that allow children to navigate risky conditions or conquer their fear of elements, such as heights or bugs, can refer to a largely internal process of "steeling oneself" to meet a challenge and may not manifest itself in any visible way, making it very difficult to observe in progress. To be fair, Hughes did not develop this taxonomy to serve as a measurement tool. The lack of any kind of hierarchical ranking of the play types is a valuable takeaway-that is, Hughes is not endorsing any one kind of play as more desirable than another, but a number of obstacles remain that make the taxonomy difficult to use in its current form as an observational framework for outdoor play.

Rubin's Play Observation Scale [24-26] is likely the typology which has been used or adapted most often in recent studies to categorize types of observed play (see Table 1). Rubin builds on the four categories of cognitive play originally posed by Smilansky [30]—functional play, constructive play, dramatic play, and games with rules - but works to more explicitly nest these play categories within the social play hierarchy advanced by Parten [28] to describe the sequential evolution of social or peer participation among preschoolers [24]. Parten described how very young children moved from solitary play and onlooker behavior on to parallel play with peers around the age of $21 / 2$ to $31 / 2$ years, and eventually on to associative and cooperative play before the age of 5 years [28]. Rubin integrated these two common, long-standing play hierarchies into a single typology for describing children's play [24], eventually expanding the play categories to include exploratory play and a generic "other" play type coded as occupied $[25,26]$ and, similar to Frost, condensing the social play categories to solitary, parallel, and group play. Rubin's Play Observation Scale (POS) was designed in part to be able to study children's socio-emotional development, and to identify children who are socially withdrawn or aggressive and potentially at risk for future psychological difficulties [25]. While the POS is useful for studying children's play behaviors, particularly indoors, like Frost's observation protocol, it does not provide enough relevant categories, or distinction within categories, to capture the full range of common outdoor activities.

Another drawback of Rubin's scale is the relegation of some commonly witnessed play behaviors to a "non-play" category, including onlooking or exploratory behaviors, active conversation, transition, and rough and tumble play (See Table 1). While Rubin eventually integrated exploratory behaviors as a legitimate play type in later versions, the other activities continue to be designated as non-play. An extensive review of the literature and our own field experience, however, supports the recognition of onlooking behaviors, rough and tumble play, and in some cases, active conversation as genuine play types or subtypes. Onlooking behavior, for example-where a child steps back from the main play 
event, occupying a safe but remote spot from which to watch others playing, is often an important bridge between episodes of involvement with others and should be acknowledged as part of the entire play cycle. Rough and tumble play is also considered to be non-play by Rubin, yet research has demonstrated that play fighting or wrestling, which takes place between smiling friends [2,31] not only helps to build children's strength and dexterity, but is a valuable play activity for developing social awareness and competence, empathy, and a sense of cooperation, and may relate to pro-social behaviors in adulthood [1,2,32,33].

Rubin's POS and other play typologies used in outdoor play research to date have largely been developed to study children's behavior in controlled indoor environments. Parten, whose social play categories were adopted by Frost and Rubin, acknowledges that indoor environments were preferred for her research as "it was thought that elements might enter into outside play which did not exist in indoor play" [28] (p. 247) and these elements were likely to confound the research which contributed to her classification system. Rubin does not explicitly state that his scale was developed for observing indoor play, but many category descriptions describe what the play behavior "in the room" might look like or how to code behavior when a child "leaves the room" [24,25]. As a result, many outdoor play studies have found it necessary to adjust these typologies to account for the unique play activities afforded by outdoor environments. As suggested by Parten, this is in part because the indoor play-type categories were not well-suited to addressing play interactions that may only be seen in outdoor settings (e.g., interactions with wildlife, picking dandelions, watching clouds, climbing trees, or water play). The authors' own attempts to fit observed outdoor play into the POS categories led to significant inconsistencies in field coding of behaviors across observers.

This difficulty in capturing the complex nature of outdoor play is reinforced by Rubin's protocol which directs observers to only categorize the most dominant play behavior observed. When there is no one dominant form of play, the observer is instructed to "code up", that is, select the category that represents the most mature social and/or cognitive category, according to a hierarchy set out by Rubin [26]. This hierarchical structure privileges one element of play over another, and so not only fails to holistically capture the outdoor play episode, but negates important elements of the child's activity. This protocol may be suitable if the ultimate goal is to assess a child's social or cognitive development (though there remains some debate over which play activities may be the most socially or cognitively mature [21]), but it is less useful for capturing the diverse and integrative nature of play afforded by an outdoor play environment.

The commonly used play typologies of Frost, Hughes, and Rubin each have drawbacks which diminish their utility both for categorizing outdoor play behaviors and as an observation tool framework for the less-structured nature of outdoor environments. Researchers interested in naturalistic observations of outdoor play therefore need a more relevant and nuanced typology and tool that can not only capture play behaviors, but also help assess whether an outdoor play space is providing environmental support for a diverse range of play activities and a diverse group of players. Another advantage of developing one standard set of outdoor play types is the opportunity to be able to consistently compare results across studies and sites, and to collectively build a larger evidence database around children's outdoor play behaviors and environments.

The new Tool for Observing Play Outdoors (TOPO) presented here outlines not only a new typology of outdoor play, but a systematic field observational protocol which utilizes these play types to effectively categorize children's activities in outdoor and naturalized play spaces. The TOPO can be used to evaluate both outdoor play behaviors, as well as the outdoor play environment itself. This observation tool can also be used to evaluate the play behaviors of children within any age group, and in both formal and informal outdoor play spaces.

\section{Development of the Tool for Observing Play Outdoors (TOPO)}

The development and refinement of the TOPO tool, and its embedded outdoor play typology, involved five distinct stages. 
Nota bene: In outlining the TOPO framework, we use the term "play episode" to describe the play activity that is captured during a single designated observation period, and the phrase "play cycle" to refer to the entire period of play activity a child undertakes within a given play session, which can comprise multiple play episodes.

\subsection{Phase 1}

To develop a new typology specifically suited to observing outdoor play behaviors, we began with an extensive review of literature related to children's play needs, the developmental role of children's play, and the growing body of research related to outdoor play. We also performed a detailed search and evaluation of existing play typologies. This work informed a systematic re-examination of three different field data sets of play behaviors collected by the authors during previous behavior mapping studies of children's outdoor play (using an adapted version of Rubin's POS typology). We subsequently flagged instances where (1) the play type codes were not capturing the essence of the outdoor play activity being observed and (2) the play episode was not being coded consistently across observers. We then examined all flagged play events, looking for commonalities that might suggest new categories or subcategories; emerging categories were then tested through an iterative process of re-coding several behavior mapping datasets.

\subsection{Phase 2}

This phase focused on establishing the primary and sub-categories of play to be included in the TOPO. Building on insights from the literature review and the field data analysis, we also considered each existing play type from the Frost, Hughes, and Rubin typologies to consider whether it was relevant for describing activities that may be commonly observed during outdoor play, as well as whether the current description was capturing outdoor play in either too narrowly or too broadly a sense. For example, as noted previously with the Hughes typology, very similar types of play (such as role play and socio-dramatic play) were separated into distinct categories; while these types of play may have subtly different meaning for the child or their development, they would be very difficult to differentiate during observations. In these cases, these types were collapsed into a single category to describe the broader type of play. Our analyses of other typologies, paired with the literature review, indicated that several previously defined play types, at least in some form, remained relevant and valuable for categorizing outdoor behaviors, including functional or locomotor play (renamed as physical play), dramatic or symbolic play (renamed as imaginative play), and games with rules (renamed as play with rules); however, the parameters of each were re-evaluated and broadened or narrowed as necessary. For example, constructive play also remained relevant to outdoor activities, but was in fact too narrowly prescribed; exploratory activities which did not result in actual "construction" were being missed.

Four key breakthroughs in the development of the TOPO tool took place during this phase. First, it became clear that we could effectively tease out distinct subtypes of play within each broader play type that would not only allow for richer and more detailed analyses of play behaviors, but could also improve inter-rater consistency when coding. A second breakthrough was a reframing of both a broader and a more nuanced description of exploratory play and several distinct subtypes, which would include constructive play but not be limited to it. The exploratory interactions between children and their environments are significant developmental activities associated with key cognitive skills, including learning and information recall $[9,34]$. Rubin uses exploratory play to capture "focused examination of an object for the purpose of obtaining visual information about its specific physical properties" [25] (p. 4), while Hughes expands this slightly to include multi-sensory manipulation of an object in order to explore its properties and inherent play possibilities [23]. While wanting to incorporate both of these forms of interaction, we struggled with the overlap with definitions of constructive play. The Exploratory Behavior Scale developed by van Schijndel, Franse, and Raijmakers [35] proved to be a valuable preliminary framework for reconceptualizing this category and its subtypes. Van Schijndel and colleagues distinguished between passive exploration, where a child attends to or engages their 
environment but does not manipulate it, and active manipulation, where a child manipulates an object or the environment in an active and attentive manner. We incorporated these distinctions in exploratory play subtypes of exploratory-passive and exploratory-active. Constructive play was then reframed as an advanced subtype of exploratory play. Constructive or construction play, defined in turn by Rubin [24] and Frost [21] as the purposeful manipulation of objects in order to construct or create something, can therefore be conceptualized as taking active exploration one step further; the child explores how to manipulate objects in the environment toward some building purpose, such as constructing a fort, a water dam, or a stone tower.

The third major change was the removal of social play as a distinct play type or as an embedded feature of the TOPO tool. Social play often refers to the way a child is engaging with and communicating (or not) with peers during a play episode, such as whether a child is playing on their own or cooperatively with others $[21,25,28]$. Both Frost and Rubin's observation tools have embedded categories of social play, where the social nature of each interaction is captured simultaneously with one of the cognitive play categories. However, in each tool, social play behaviors are not treated consistently; some social aspects of play are outlined as social play categories, while others are considered other play or non-play, such as active conversation, onlooker behaviors, and even rough and tumble games which have a significant social component [2]. Hughes treated social play as a distinct play type, covering play interactions where rules and criteria for social engagement are explored and negotiated [23]. While we believe the social nature of play is an essential characteristic of children's play to capture and study, the TOPO acknowledges that all types of play can be characterized by the social interaction that takes place during, or even helps to define a play episode. As suggested by Burdette and Whitaker [8], all play with others involves some form of a social problem; children must constantly discuss and negotiate what and how to play. These social interactions help children to learn how to cooperate and compromise, build their capacity for flexibility and empathy, and give them practice regulating their emotions and desires [8]. Integral social exchanges are already embedded in several of the TOPO play types, including play with rules and some forms of imaginative play. We have therefore chosen not to treat the social context of play as its own play type, but rather as an essential element woven into every play episode which would be better and more consistently captured using a complementary social interaction scale. The choice of social or peer interaction tool should align with the goals of the study, as well as the age group of the players being observed. A full or modified version of Parten's social play categories remains a helpful framework (See Table 1).

The final innovation during this development phase was the expansion of the observation protocol to allow for up to two play types (with subtypes as relevant or desired) to be recorded for each play episode. Conceptually, we felt this change would both more accurately capture the complex nature of children's outdoor play behaviors and largely negate the need for a hierarchical structure in order to improve the reliability of field coding. This protocol change was subsequently tested in Phases 3 and 5.

At the completion of Phase 2, we had established an initial outdoor play typology (TOPO Version 1; See Table 2) comprised of eight primary play categories and 29 associated sub-types. 
Table 2. Iterations of the Tool for Observing Play Outdoors (TOPO).

\begin{tabular}{|c|c|c|c|c|c|}
\hline \multicolumn{2}{|c|}{ TOPO Version 1} & \multicolumn{2}{|c|}{ TOPO Version 2} & \multicolumn{2}{|c|}{ TOPO Version 3} \\
\hline Locomotor play & $\begin{array}{l}\text { Gross motor } \\
\text { Fine motor } \\
\text { Vestibular } \\
\text { Rough \& Tumble } \\
\text { Transition }\end{array}$ & Locomotor play & $\begin{array}{l}\text { Gross motor } \\
\text { Fine motor } \\
\text { Vestibular } \\
\text { Rough E Tumble }\end{array}$ & Physical play & $\begin{array}{l}\text { Gross motor } \\
\text { Fine motor } \\
\text { Vestibular } \\
\text { Rough E Tumble }\end{array}$ \\
\hline Exploratory play & $\begin{array}{l}\text { Passive } \\
\text { Active } \\
\text { Construction }\end{array}$ & Exploratory play & $\begin{array}{l}\text { Passive } \\
\text { Active } \\
\text { Construction } \\
\text { Artistic }\end{array}$ & Exploratory play & $\begin{array}{l}\text { Passive } \\
\text { Active } \\
\text { Construction }\end{array}$ \\
\hline Imaginative play & $\begin{array}{l}\text { Solo } \\
\text { Group }\end{array}$ & Imaginative play & $\begin{array}{l}\text { Symbolic } \\
\text { Socio-dramatic } \\
\text { Fantasy }\end{array}$ & Imaginative play & $\begin{array}{l}\text { Symbolic } \\
\text { Socio-dramatic } \\
\text { Fantasy }\end{array}$ \\
\hline Play with Rules & $\begin{array}{l}\text { Formal } \\
\text { Informal }\end{array}$ & Play with Rules & $\begin{array}{l}\text { Formal } \\
\text { Informal }\end{array}$ & Play with Rules & $\begin{array}{l}\text { Conventional } \\
\text { Organic }\end{array}$ \\
\hline $\begin{array}{l}\text { Communication } \\
\text { play }\end{array}$ & $\begin{array}{l}\text { Peer-Social } \\
\text { Adult-Social } \\
\text { Play } \\
\text { Environment } \\
\text { Cowabunga } \\
\text { Instructive/Lesson } \\
\text { Self-talk } \\
\text { Care }\end{array}$ & $\begin{array}{l}\text { Communication } \\
\text { play* }\end{array}$ & $\begin{array}{l}\text { Performance } \\
\text { Social conversation }\end{array}$ & Expressive play & $\begin{array}{l}\text { Performance } \\
\text { Artistic } \\
\text { Language } \\
\text { Conversation }\end{array}$ \\
\hline Performance play & [no defined subtypes] & $\begin{array}{l}\text { Digital play } \\
\text { Stewardship }\end{array}$ & $\begin{array}{l}\text { [no defined subtypes] } \\
\text { [no defined subtypes] }\end{array}$ & $\begin{array}{l}\text { Digital play } \\
\text { Bio play }\end{array}$ & $\begin{array}{l}\text { Device } \\
\text { Augmented } \\
\text { Embedded } \\
\text { Plants } \\
\text { Wildlife } \\
\text { Care }\end{array}$ \\
\hline Restorative play & $\begin{array}{l}\text { Resting/Sitting } \\
\text { Retreat } \\
\text { Reading/writing } \\
\text { Eating/Drinking }\end{array}$ & Restorative play & $\begin{array}{l}\text { Resting } \\
\text { Retreat } \\
\text { Reading } \\
\text { Eating }\end{array}$ & Restorative play & $\begin{array}{l}\text { Resting } \\
\text { Retreat } \\
\text { Reading } \\
\text { Onlooking }\end{array}$ \\
\hline Non-play & $\begin{array}{l}\text { Self-care } \\
\text { Distress } \\
\text { Transition } \\
\text { Other }\end{array}$ & Non-play & $\begin{array}{l}\text { Self-care } \\
\text { Distress } \\
\text { Transition } \\
\text { Other }\end{array}$ & Non-play & $\begin{array}{l}\text { Self-care } \\
\text { Nutrition } \\
\text { Distress } \\
\text { Aggression } \\
\text { Transition } \\
\text { Other }\end{array}$ \\
\hline
\end{tabular}

* Most Communications subtypes were moved to the separate Play Communication Typology (See Appendix A).

\subsection{Phase 3}

The third phase of development involved testing and refining of this initial proposed TOPO typology. To strengthen and refine the play types, we conducted three separate rounds of reliability analyses (two within Phase 3 and one within Phase 5). For each reliability round, the two authors used the TOPO to independently code an identical set of previously recorded outdoor play episodes from three different outdoor play sites. A minimum of 150 records of play episodes were selected at random from datasets of 800 or more episodes for each round. For each play episode, the researchers were given the option to designate up to two play types (Play Type 1 and Play Type 2), each with a primary play type and a subtype. For each reliability round, the codes from both researchers were compared and scored on the degree to which there was agreement. The researchers then reviewed all records where there were inconsistencies in coding; in some cases, this review led to the development of a new play type or subtype, whereas in other cases it led to the inclusion of greater detail within the play type descriptions for additional clarity.

The first reliability round assessed the play types in TOPO Version 1 (See Table 2) and yielded an overall agreement score of 0.746 , revealing that the two researchers were coding the same two primary and subtypes approximately $75 \%$ of the time (See Table 3 ). However, while agreement for the primary and subtype categories for Play Type 1 were very high $(94.1 \%$ and $84.3 \%$, respectively; see Table 2), coding agreement for both primary and subtypes for Play Type 2 was fairly low $(65.7 \%$ and $54.5 \%$, respectively). [Note: there was no hierarchical distinction made between Play Types 1 and 2; the order in which the coders listed play types for an episode was not considered, only whether one or both of the play type codes from one rater matched one or both from the other]. 
Table 3. Reliability rounds summary.

\begin{tabular}{lccccccc}
\hline & \multicolumn{7}{c}{ Inter-Rater Agreement } \\
\hline Reliability Round & $\begin{array}{c}\text { Play Type 1 } \\
\text { Primary }\end{array}$ & $\begin{array}{c}\text { Play Type 1 } \\
\text { Subtype }\end{array}$ & $\begin{array}{c}\text { Play Type 2 } \\
\text { Primary }\end{array}$ & $\begin{array}{c}\text { Play Type 2 } \\
\text { Subtype }\end{array}$ & $\begin{array}{c}\text { Overall } \\
\text { IRR }\end{array}$ & $\begin{array}{c}\text { Overall: Primary } \\
\text { Play types }\end{array}$ & $\begin{array}{c}\text { Overall: Play } \\
\text { Subtypes }\end{array}$ \\
\hline Round 1 (Phase 3) & 0.941 & 0.843 & 0.657 & 0.545 & 0.746 & 0.799 & 0.694 \\
Round 2 (Phase 3) & 0.922 & 0.901 & 0.681 & 0.56 & 0.78 & 0.819 & 0.74 \\
Round 3 (Phase 5) & 1 & 0.991 & 0.735 & 0.615 & 0.835 & kappa: 0.80 & kappa: 0.75 \\
\hline
\end{tabular}

Reflecting on the coding inconsistencies, the researchers made several key changes, the largest of which was a substantial revision of the communication play category (See Table 2). A review revealed that inter-rater reliability decreased significantly when observers captured some non-essential discussions happening among the players using the communication play category. For example, if two children were observed talking about the timing of their lunch break while collectively building a sandcastle, a coder might use the communication play-social conversation combination as one of the two designated play types. Similar to social play, many forms of observed communication were a valuable element of the play, but did not represent a distinct play type; the communication play code was also superseding other play types which better captured the essence of the play episode, as well as leading to significant coding inconsistencies. While we kept the communication play category within the typology (later expanded and renamed as expressive play, see Table 2), this play type was limited to episodes where the communication was a primary component of the play. To capture all other forms of communication taking place within or around an observed play episode, we developed a separate, complementary Play Communication Typology (PCT) which can be used in concert with the TOPO (see Appendix A for more details on the PCT).

Other changes included moving transition from a subtype of physical play (where it was initially placed because most transitions between play settings or in and out of the play space itself involved walking) to a subtype of non-play, which better reflected its character. The subtypes of imaginative play were also initially set out as solo and group; however, we realized that these subtypes reflected the social interaction of the play, which, as noted earlier, is better captured through a separate peer interaction measure. The subtypes would be more informative if they provided distinctions between common types of imaginative play. A review of the literature and other play typologies led to the development of three subtypes which represented fundamental, as well as observable differences in children's pretend play activities—symbolic, socio-dramatic, and fantasy play (See Table 2).

A second round of reliability coding was performed by the two authors on Version 2 of the TOPO, yielding an overall agreement score of $78.0 \%$ (See Table 3). This overall score was an improvement from Round 1 and reflected greater agreement among Play Type 1 codes; however, agreement among the primary and subtype categories for Play Type 2 remained fairly low (68.1\% and 56.0\%). Removing play-related communication to a separate measure did significantly improve the level of agreement, particularly within the Play Type 2 codes, as raters were not having to use a second play type to capture communication taking place around the play event. When all play episodes were then coded by the two researchers separately using the new Play Communication Typology, inter-rater agreement was immediately very high, showing $86.4 \%$ agreement among coders. Cohen's kappa calculated for play communication coding was 0.80 , an extremely high level of agreement.

Refinements made after the second reliability round to address continuing coding discrepancies included more clearly defined subtypes; for example, more clearly distinguishing between behaviors that fall under exploratory-active versus exploratory-constructive. It was also decided that observers would try whenever possible to define a second primary play type (with associated subtype) for each observed play event, as most reliability errors were a result of one rater including a second play type when the other did not. 


\subsection{Phase 4}

After these small revisions to Version 2, the TOPO typology was shared with an external panel of 10 researchers, play providers, and design practitioners who are intimately familiar with children's outdoor play behaviors. Reviewers were asked to consider the typology in relation to their experience with outdoor play, and to answer a series of questions related to potential gaps or mischaracterizations within the play types, the value of a hierarchical framework, and the utility of the typology as an observation tool. These reviews yielded substantial insights which prompted changes and additions to the play types to provide additional clarity, to improve concept validity within subtypes, and to address gaps. These changes are outlined in TOPO Version 3 (See Table 2). One significant change was renaming and expanding communication play to expressive play, in order to better describe and include a broader range of expressive and artistic play behaviors common among children; language play and artistic play were added as additional distinct subtypes (and social conversation was simplified to conversation). A few other adjustments were made, including moving nutrition (eating and drinking activities) from a subtype of restorative play to a non-play subtype, and the addition of onlooking as a new subtype of restorative play (see below for more details). Exploratory-passive was renamed to exploratory-sensory to better reflect the intentional interaction with an object or environment using one or more senses (but without active manipulation). Distinct subtypes were also developed for digital play to reflect the different interfaces between digital elements and the physical environment that can occur in outdoor play spaces (see Table 2).

However, the largest insight arising from the expert review was the inability of the current typology to capture the playful interactions we often see outdoors between children and living things, such as plants, bugs, and birds. These interactions would be rightfully captured under exploratory play, but this play type was not sufficient on its own to reflect the essence or importance of these encounters with plants and wildlife that is often unique to outdoor environments. We subsequently expanded the original play type stewardship, which was meant to capture interactions that involved care of living things or the environment generally, to a new primary play type called bio play. More details on this new outdoor play type can be found below.

These changes were incorporated into Version 3, the final iteration of the TOPO tool (See Table 2).

\subsection{Phase 5}

For this last phase of development, a final reliability round was carried out by the two authors using TOPO Version 3 (See Table 2). Inter-rater agreement across all measures showed marked improvement (See Table 3). There was 100\% agreement around the primary category for Play Type 1, and $99 \%$ agreement on its associated subtype. Agreement on Play Type 2 was improved from previous rounds, but still lower than that of Play Type 1 . Coders agreed on the second primary play type $73.5 \%$ of the time, and $61.5 \%$ on the second subtype. Investigation of the coding discrepancies revealed that this lower agreement rate for Play Type 2 was primarily the result of two conditions: either one coder had decided not to use a second play type to categorize the play episode, or else the raters agreed on the second primary play type but selected different subtypes within the same category, such as one coding an episode as exploratory-active, while the other coded it as exploratory-constructive. Each minor disagreement was revisited to understand the reason for the inconsistency, and both the protocol and the subtype descriptions were further refined to minimize future discrepancies. As part of this work, the authors identified common intersections between play types that tend to be observed during outdoor play to be included as part of training materials for the tool; some of these intersections are outlined in Table 4. However, when we calculated the overall agreement for the primary play types, raters agreed $86.8 \%$ of the time, and overall agreement on all subtypes was $80.3 \%$; to ensure that these generally high levels of agreement were not a result of chance, we calculated Cohen's kappa coefficient for both primary and subtypes. The kappa value for agreement among primary play types was 0.80 , demonstrating almost perfect agreement, and 0.75 for subtypes which reflects substantial agreement among raters [36]. The final version of the typology therefore produced sufficiently high 
levels of inter-rater agreement and the ease and reliability of coding was greatly improved from previous versions. Table 3 outlines the final iteration of the Tool for Observing Play Outdoors; detailed descriptions of each play type are outlined below.

\subsection{Validation of the TOPO}

While developing this typology, efforts were made to follow a course of action that would result in a valid and reliable tool that could be used consistently by multiple researchers and garner-consistent results across many types of studies. Cresswell and Poth outline nine strategies for effectively validating qualitative data and recommend that researchers utilize at least two of the recommended strategies in any given study [37]. Our development approach focused on five of those strategies: corroboration of evidence through triangulation, prolonged engagement, and persistent observation in the field, generating a rich, thick description, having a peer review or debriefing of the data and research process, and enabling external audits [37] (pp. 260-263). Below is a snapshot of how we aimed to fulfill each strategy:

i. Corroboration of evidence through triangulation: The authors carried out an extensive review of literature related to play and children's developmental needs, as well as a detailed examination of other play typologies. Results of these reviews were continually cross-referenced with previously collected field data of children's play behaviors and feedback from experts; all types of data were examined for corroboration and refinement of emerging outdoor play types.

ii. Prolonged engagement and persistent observation in the field: Both authors had extensive experience collecting outdoor play type data from multiple outdoor sites both before and during the development of the outdoor play typology. Large data sets of outdoor play behaviors were also re-examined multiple times to ensure we had extensive knowledge of the full range of play behaviors observed in the field.

iii. Generating a rich, thick description: To provide transparency around its development, as well as to support transferability of the tool to multiple contexts, we produced detailed accounts of the process used to develop and test the tool, substantial descriptions of the play types, clear comparisons to previous play typologies, and outlined illustrative examples of each play type.

iv. Having a peer review or debriefing of the data and research process: The researchers jointly discussed the process and the findings on continual basis, and also met periodically with colleagues to discuss the development of the typology. These were informal sessions meant to confirm proposed development processes and discuss alternative strategies.

v. Enabling external audits: Phase four consisted of an external audit where feedback on the typology (through a series of guided questions) was solicited from a panel of 10 professionals who had no connection to the study. This external review was extremely valuable for the validation process and led to several adjustments to the typology.

\section{Outdoor Play Type Definitions}

This section provides a fuller description of each of the nine primary play types in the TOPO (See Table 4). The first five play types largely correspond to categories of play also incorporated in some way in other play typologies—physical play, exploratory play, imaginative play, play with rules, and expressive play. The next three play types-bio play, restorative play, and digital play - are unique to the $\mathrm{TOPO}$ and represent newly derived categories which reflect either play behaviors that are particularly common during outdoor play, or else the changing nature of both play and play environments in the 21st century. The ninth and final category is a non-play category, which allows observers to code behaviors that are common to outdoor play environments, but which are generally not considered to be play activities. Details and examples of each primary play type and their designated subtypes are outlined in Table 4. 


\subsection{Physical Play}

This play type captures outdoor play activity that is mostly physical in nature, where children's use or testing of their bodies and their physical capabilities are integral to the play event. Sometimes categorized as locomotor play, movement play, or functional play in other typologies, this form of play allows children to explore their physical capabilities, make sense of their bodies, and develop increased strength, dexterity, agility, balance, and flexibility [2,3,9]. Physical play applies to behaviors such as running and climbing where children engage their large muscle systems, or play which involves finer motor movements and hand-eye coordination through the gripping, movement, and manipulation of small objects and tools [1,34]. This play type also captures vestibular play, such as balancing, spinning, or rocking; through such movements, children sense and explore their own position and movement in space, and develop a sense of equilibrium and postural control [38]; vestibular movements have also been linked to key developments in cognition and spatial behaviors [39]. Activities that involve playful physical contact, such as mock fighting or wrestling, are also captured as physical play. These activities, which take place "between friends who stay friends" [2] (p.89), are not actually acts of aggression as they can often be interpreted by adults, but rather an unappreciated type of play that helps children to develop social awareness and a sense of fairness and cooperation [2,21]. Such encounters can be so important to children's social development that it has, at times, been categorized as a form of social play [32,40]. However, we capture these activities here as physical play, as they manifest primarily through physical contact.

Through physically embodied play, we use the movement of our bodies as a way of knowing, of understanding not only our own selves but our relationship to time, space, and other people [2]. While many of these physical play activities reveal themselves primarily through physical movement, we acknowledge that these actions often have associated cognitive, social, and emotional development components $[9,34]$. Jumping off of a high platform uses and builds physical capabilities, but to the child it can also be an embodied experience of gravity, and the result of conquering one's nerves. Research on brain development confirms that "movement play lights up the brain and fosters learning, innovation, flexibility, adaptability, and resilience" [2] (p. 84).

Physical play captures a diverse range of physically involved activities, including for children of different ages and those with physical impairments or delays. Physical play activities can also be distilled into four distinct subtypes-gross motor, fine motor, vestibular, and rough and tumble. Detailed descriptions for and examples of these subtypes are outlined in Table 4. 
Table 4. TOPO outdoor play types summary.

\begin{tabular}{|c|c|c|c|c|c|}
\hline Primary Play Type & Play Subtype & Description & Examples & $\begin{array}{l}\text { Common Intersections } \\
\text { with other Play Types }\end{array}$ & $\begin{array}{l}\text { Comparable Categories } \\
\text { from Other Typologies }\end{array}$ \\
\hline \multirow[t]{4}{*}{ Physical Play } & Gross motor & $\begin{array}{l}\text { activities that utilize large muscles } \\
\text { and/or require whole body movement; } \\
\text { not just casual movement of an object, } \\
\text { but activities which might tax muscles } \\
\text { or help to improve gross motor skills; } \\
\text { can also include large muscle activities } \\
\text { that require hand/eye coordination }\end{array}$ & $\begin{array}{l}\text { climbing, running, } \\
\text { throwing/catching, lifting, } \\
\text { carrying heavy loads, crawling, } \\
\text { swinging an item such as a bat } \\
\text { or branch, jumping, kicking, or } \\
\text { riding a bicycle }\end{array}$ & $\begin{array}{l}\text { play with rules: as in } \\
\text { chasing games }\end{array}$ & $\begin{array}{l}\text { functional play; locomotor } \\
\text { play; exercise play; } \\
\text { movement play; } \\
\text { deep play }\end{array}$ \\
\hline & Fine motor & $\begin{array}{l}\text { activities that involve the use of smaller } \\
\text { muscle movements and hand/eye } \\
\text { coordination, or which help develop } \\
\text { finer motor skills; can include picking } \\
\text { up or manipulating small objects in the } \\
\text { environment }\end{array}$ & $\begin{array}{l}\text { using a spoon or stick to stir } \\
\text { water or mud, using a small } \\
\text { shovel to scoop sand, picking up } \\
\text { leaves, balls or other small } \\
\text { loose parts }\end{array}$ & $\begin{array}{l}\text { exploratory-active: as in } \\
\text { stirring a bowl of dirt and } \\
\text { water to make mud }\end{array}$ & $\begin{array}{l}\text { functional play; } \\
\text { object play }\end{array}$ \\
\hline & Vestibular & $\begin{array}{l}\text { activities which test or improve a child's } \\
\text { sense of balance and/or reinforce their } \\
\text { relationship to the earth; usually } \\
\text { involve movement of the head or quick } \\
\text { movements in multiple directions }\end{array}$ & $\begin{array}{l}\text { balancing, spinning, twirling, } \\
\text { sliding, rolling, rocking, or } \\
\text { hanging upside down; play } \\
\text { activities could include } \\
\text { balancing on a log or bridge, } \\
\text { going back and forth on a glider } \\
\text { or see saw, rocking in a chair or } \\
\text { hammock, riding a swing, doing } \\
\text { somersaults or cartwheels, } \\
\text { walking on their hands, } \\
\text { skipping, using monkey bars or } \\
\text { hanging from a tree branch }\end{array}$ & & $\begin{array}{l}\text { functional play; locomotor } \\
\text { play; exercise play; } \\
\text { movement play; } \\
\text { deep play }\end{array}$ \\
\hline & Rough E Tumble & $\begin{array}{l}\text { engagement in playful or mock fighting } \\
\text { or wrestling "between friends who stay } \\
\text { friends" [2] (p. 89) or more broadly } \\
\text { playful physical contact such as tickling. } \\
\text { Note: needs to be distinguished from } \\
\text { actual aggression, which is not meant as } \\
\text { a playful exchange between friends and } \\
\text { is categorized within OPOS as non-play }\end{array}$ & $\begin{array}{l}\text { play fighting, wrestling, tussling, } \\
\text { tumbling, tickling, } \\
\text { "sword" fighting }\end{array}$ & $\begin{array}{l}\text { imaginative: as in play } \\
\text { fighting within a } \\
\text { superhero scenario }\end{array}$ & social play; play fighting \\
\hline
\end{tabular}


Table 4. Cont.

\begin{tabular}{|c|c|c|c|c|c|}
\hline Primary Play Type & Play Subtype & Description & Examples & $\begin{array}{l}\text { Common Intersections } \\
\text { with other Play Types }\end{array}$ & $\begin{array}{l}\text { Comparable Categories } \\
\text { from Other Typologies }\end{array}$ \\
\hline \multirow[t]{3}{*}{ Exploratory Play } & Sensory & $\begin{array}{l}\text { playful but primarily passive (i.e., } \\
\text { non-manipulative) exploration of an } \\
\text { object or environment, often through } \\
\text { one or more senses; includes } \\
\text { interactions where the child appears to } \\
\text { be receiving sensory information about } \\
\text { the object or environment where their } \\
\text { attention is focused, such as rubbing a } \\
\text { plant part to feel its fuzziness or } \\
\text { roughness; also includes when a child } \\
\text { is walking through an environment but } \\
\text { clearly taking in or exploring } \\
\text { the setting }\end{array}$ & $\begin{array}{l}\text { rubbing a leaf blade, splashing } \\
\text { feet through flowing water, } \\
\text { searching the ground for bugs } \\
\text { or flowers, running mud } \\
\text { through their fingers, petting } \\
\text { an animal }\end{array}$ & $\begin{array}{l}\text { bio play-plants or bio } \\
\text { play-wildlife: as in playing } \\
\text { with plant or animal life }\end{array}$ & object play; exploration \\
\hline & Active & $\begin{array}{l}\text { playful activities that involve active } \\
\text { manipulation of an object or the } \\
\text { environment where the child is paying } \\
\text { attention to the outcome of the action, } \\
\text { movement, or interaction These } \\
\text { activities may have some goal, such as } \\
\text { filling a pail with shovelfuls of sand, } \\
\text { but where the child is not necessarily } \\
\text { building or constructing something. }\end{array}$ & $\begin{array}{l}\text { shoveling sand into a pail, } \\
\text { digging a hole in a pile of } \\
\text { gravel, floating a boat down a } \\
\text { stream, collecting rocks and } \\
\text { leaves, using a tree branch as } \\
\text { broom to sweep dirt, driving a } \\
\text { toy truck through mud, pulling } \\
\text { the petals off a flower, stirring } \\
\text { water and dirt together to } \\
\text { make mud }\end{array}$ & $\begin{array}{l}\text { imaginative: as in a } \\
\text { "parent" baking a mud } \\
\text { "pie" to serve to family } \\
\text { for dinner }\end{array}$ & $\begin{array}{l}\text { object play; sensory } \\
\text { motor; cause and effect } \\
\text { play; construction play; } \\
\text { mastery play }\end{array}$ \\
\hline & Constructive & $\begin{array}{l}\text { activities where the child is } \\
\text { manipulating objects in or the } \\
\text { environment itself for the purpose of } \\
\text { physically building or construct } \\
\text { something, or else the thoughtful } \\
\text { destruction or taking apart of } \\
\text { something; includes when a child is } \\
\text { playing with or putting together any } \\
\text { kind of puzzle. }\end{array}$ & $\begin{array}{l}\text { using rocks to build a dam in a } \\
\text { stream, using loose parts to } \\
\text { build a fort, piling rocks up to } \\
\text { build a pyramid, piling up } \\
\text { sticks to build a "fire", } \\
\text { arranging crates to define a } \\
\text { "house", moving pylons to } \\
\text { create a racetrack }\end{array}$ & $\begin{array}{l}\text { physical play types: as in } \\
\text { picking up or } \\
\text { manipulating small or } \\
\text { large objects as part of (de) } \\
\text { construction activities } \\
\text { imaginative-play types: as } \\
\text { in constructing a tower to } \\
\text { use in their role as prince } \\
\text { or princess }\end{array}$ & $\begin{array}{l}\text { construction play; } \\
\text { constructive play; mastery } \\
\text { play; cause and effect play; } \\
\text { creative play; deep play }\end{array}$ \\
\hline
\end{tabular}


Table 4. Cont

\begin{tabular}{|c|c|c|c|c|c|}
\hline Primary Play Type & Play Subtype & Description & Examples & $\begin{array}{l}\text { Common Intersections with } \\
\text { other Play Types }\end{array}$ & $\begin{array}{l}\text { Comparable Categories } \\
\text { from Other Typologies }\end{array}$ \\
\hline \multirow[t]{3}{*}{ Imaginative Play } & Symbolic & $\begin{array}{l}\text { where the play involves using an object, } \\
\text { action or idea in the environment as a } \\
\text { symbol for something else. This } \\
\text { pretense is essentially embedded in the } \\
\text { other two imaginative subtypes, but } \\
\text { this is to be used when there is no } \\
\text { observable evidence of socio-dramatic or } \\
\text { fantasy play elements }\end{array}$ & $\begin{array}{l}\text { using a piece of wood to } \\
\text { symbolize a person, or a piece } \\
\text { of string to symbolize a } \\
\text { wedding ring, or a banana to } \\
\text { play the role of a phone }\end{array}$ & $\begin{array}{l}\text { exploratory-active or } \\
\text { exploratory-constructive: as in } \\
\text { turning mud into "cake } \\
\text { batter" or constructing a } \\
\text { "house" out of } \\
\text { cardboard boxes }\end{array}$ & $\begin{array}{l}\text { creative play; dramatic } \\
\text { play; symbolic play }\end{array}$ \\
\hline & Socio-dramatic & $\begin{array}{l}\text { where the imaginative play involves } \\
\text { playing or trying out typical social, } \\
\text { domestic or interpersonal experiences } \\
\text { or roles they may experience as adults }\end{array}$ & $\begin{array}{l}\text { playing "house", going } \\
\text { shopping, pretending to be } \\
\text { parents, organizing or cooking } \\
\text { a meal, pretending to have a } \\
\text { family fight }\end{array}$ & $\begin{array}{l}\text { exploratory-active or } \\
\text { exploratory-constructive: as in } \\
\text { pretending a plate of stones is } \\
\text { "supper" for their children or } \\
\text { arranging logs to form the } \\
\text { outline of their "house" }\end{array}$ & $\begin{array}{l}\text { symbolic play; dramatic } \\
\text { play; role play; creative } \\
\text { play; fantasy play; } \\
\text { role play }\end{array}$ \\
\hline & Fantasy & $\begin{array}{l}\text { where the imaginative play involves } \\
\text { performing or playing with situations } \\
\text { that are not personal or domestic, or } \\
\text { enacting something that is unlikely to } \\
\text { occur in real life. }\end{array}$ & $\begin{array}{l}\text { playing characters from Harry } \\
\text { Potter, pretending to be a } \\
\text { princess, a wizard, an animal, } \\
\text { or a space pilot }\end{array}$ & $\begin{array}{l}\text { exploratory-active or } \\
\text { exploratory-constructive: as in } \\
\text { pretending sticks are wizards' } \\
\text { wands, or a line of wood } \\
\text { stumps as their castle moat }\end{array}$ & $\begin{array}{l}\text { symbolic play; dramatic } \\
\text { play; creative play; fantasy } \\
\text { play; role play }\end{array}$ \\
\hline \multirow[t]{2}{*}{ Play with Rules } & Organic & $\begin{array}{l}\text { two or more kids are agreeing to play } \\
\text { or challenge each other in a certain way, } \\
\text { where they develop, negotiate and } \\
\text { even change the rules as they go }\end{array}$ & $\begin{array}{l}\text { developing a game where } \\
\text { superheroes chase villains, or } \\
\text { racing toy cars down a plank, or } \\
\text { seeing who can climb highest in } \\
\text { a tree }\end{array}$ & $\begin{array}{l}\text { physical play types: as in } \\
\text { running, wresting, or } \\
\text { spinning as part of a made up } \\
\text { game or challenge }\end{array}$ & $\begin{array}{l}\text { games with rules; social } \\
\text { play; locomotor play }\end{array}$ \\
\hline & Conventional & $\begin{array}{l}\text { two or more kids playing games that } \\
\text { have common, universal or } \\
\text { well-known rules that the players } \\
\text { understand before commencing. Note: } \\
\text { if the play morphs into an activity } \\
\text { where the rules are changed or } \\
\text { renegotiated so they no longer follow } \\
\text { the traditional rules of play then in } \\
\text { become play with rules-informal }\end{array}$ & $\begin{array}{l}\text { soccer, baseball, tag, capture the } \\
\text { flag, hide and seek }\end{array}$ & $\begin{array}{l}\text { physical-gross: as in running to } \\
\text { play soccer or tag }\end{array}$ & $\begin{array}{l}\text { games with rules; social } \\
\text { play; locomotor play }\end{array}$ \\
\hline
\end{tabular}


Table 4. Cont.

\begin{tabular}{|c|c|c|c|c|c|}
\hline Primary Play Type & Play Subtype & Description & Examples & $\begin{array}{l}\text { Common Intersections } \\
\text { with other Play Types }\end{array}$ & $\begin{array}{l}\text { Comparable Categories } \\
\text { from Other Typologies }\end{array}$ \\
\hline \multirow[t]{3}{*}{ Bio Play } & Plants & $\begin{array}{l}\text { where a child observes, discusses, or } \\
\text { interacts with a living plant }\end{array}$ & $\begin{array}{l}\text { picking a fruit, closely examining } \\
\text { a leaf or flower, or exploring or } \\
\text { commenting on some } \\
\text { characteristic of the vegetation }\end{array}$ & $\begin{array}{l}\text { exploratory-active: when they } \\
\text { manipulate portions of the } \\
\text { plant, or exploratory sensory: } \\
\text { when they comment that a } \\
\text { leaf "feels fuzzy" }\end{array}$ & \\
\hline & Wildlife & $\begin{array}{l}\text { when a child is keenly observing or } \\
\text { interacting with wildlife in the same } \\
\text { environment including animals, birds } \\
\text { and bugs (that are not a domestic pets) }\end{array}$ & $\begin{array}{l}\text { catching small animals or bugs } \\
\text { such as fireflies, moths, frogs, or } \\
\text { crawdads; closely observing a } \\
\text { bird or a turtle; poking a stick in } \\
\text { the water to watch frog eggs } \\
\text { wobble; looking under a log to } \\
\text { see bugs }\end{array}$ & $\begin{array}{l}\text { exploratory-active: when they } \\
\text { pick up a bug, or } \\
\text { manipulate the } \\
\text { environment to better see } \\
\text { an insect; exploratory sensory: } \\
\text { as in when they are actively } \\
\text { watching a bird, bug or } \\
\text { animal }\end{array}$ & \\
\hline & Care & $\begin{array}{l}\text { a child acts in a way that demonstrates } \\
\text { care or stewardship of the environment, } \\
\text { or an appreciation of nature }\end{array}$ & $\begin{array}{l}\text { watering a plant or planting an } \\
\text { acorn, building a home for a } \\
\text { turtle, rescuing a caterpillar that } \\
\text { is crawling along a pathway, } \\
\text { picking up a piece of litter and } \\
\text { placing it in the recycling bin }\end{array}$ & $\begin{array}{l}\text { exploratory-active: when they } \\
\text { are filling a pail in order to } \\
\text { water a plant, or gathering } \\
\text { grass to feed a caterpillar }\end{array}$ & \\
\hline \multirow[t]{2}{*}{ Expressive Play } & Performance & $\begin{array}{l}\text { intentionally performing for others in } \\
\text { some way }\end{array}$ & $\begin{array}{l}\text { includes singing, drama/acting, } \\
\text { dancing, playing music, juggling, } \\
\text { or even hamming it up for the } \\
\text { entertainment of others }\end{array}$ & & $\begin{array}{l}\text { musical play; creative } \\
\text { play; symbolic play; } \\
\text { semiotic play }\end{array}$ \\
\hline & Artistic & $\begin{array}{l}\text { manipulating the environment } \\
\text { specifically for an artistic, creative or } \\
\text { aesthetic outcome; includes } \\
\text { mark-making and drawing }\end{array}$ & $\begin{array}{l}\text { arranging leaves in a pattern, } \\
\text { drawing spirals or pictures in the } \\
\text { dirt or sand, painting or drawing } \\
\text { pictures, making a pattern in the } \\
\text { mud with footprints, or a } \\
\text { sculpture out of sand }\end{array}$ & $\begin{array}{l}\text { exploratory-active or } \\
\text { exploratory-constructive: as } \\
\text { in building of a patterned } \\
\text { pyramid out of colored } \\
\text { blocks, or designing a castle } \\
\text { complex out of sand }\end{array}$ & $\begin{array}{l}\text { creative play; symbolic } \\
\text { play; semiotic play }\end{array}$ \\
\hline
\end{tabular}


Table 4. Cont.

\begin{tabular}{|c|c|c|c|c|c|}
\hline Primary Play Type & Play Subtype & Description & Examples & $\begin{array}{l}\text { Common Intersections with } \\
\text { other Play Types }\end{array}$ & $\begin{array}{l}\text { Comparable Categories } \\
\text { from Other Typologies }\end{array}$ \\
\hline \multirow[t]{2}{*}{ Expressive Play } & Language & $\begin{array}{l}\text { activities involving the playful use or } \\
\text { testing of sound, words and/or } \\
\text { language }\end{array}$ & $\begin{array}{l}\text { making up rhymes or poems, } \\
\text { singing to themselves or with } \\
\text { others, chanting, making } \\
\text { up/telling jokes or stories, }\end{array}$ & $\begin{array}{l}\text { exploratory-active or } \\
\text { exploratory-constructive: as in } \\
\text { using a blade of grass or branch } \\
\text { to make a whistling sound, } \\
\text { drumming on a pot with a spoon }\end{array}$ & $\begin{array}{l}\text { storytelling; narrative } \\
\text { play; communication play; } \\
\text { musical play; } \\
\text { recapitulative play; } \\
\text { semiotic play }\end{array}$ \\
\hline & Conversation & $\begin{array}{l}\text { activities where the primary playful } \\
\text { interaction is social conversation with } \\
\text { other children or adults but does not } \\
\text { involve any role play, is not } \\
\text { supplemental to the play, or fall under } \\
\text { other expressive play subtypes }\end{array}$ & $\begin{array}{l}\text { includes two or more children } \\
\text { sitting around a stump circle } \\
\text { talking about a mutually } \\
\text { attended event, or discussing } \\
\text { their day with a parent }\end{array}$ & $\begin{array}{l}\text { restorative-resting and/or non-play } \\
\text { nutrition: as is a small or large } \\
\text { group talking together while } \\
\text { sitting in the shade or eating } \\
\text { a snack }\end{array}$ & $\begin{array}{l}\text { communication play; } \\
\text { active conversation }\end{array}$ \\
\hline \multirow[t]{4}{*}{ Restorative Play } & Resting & $\begin{array}{l}\text { includes activities where a child is } \\
\text { clearly taking a mental and/or break } \\
\text { or rest }\end{array}$ & $\begin{array}{l}\text { includes sitting, laying down, } \\
\text { daydreaming, talking quietly } \\
\text { to themselves (not paired } \\
\text { with another play activity), or } \\
\text { even quietly staring } \\
\text { into space }\end{array}$ & $\begin{array}{l}\text { non-play nutrition, } \\
\text { exploratory-sensory or } \\
\text { restorative-onlooking: as in sitting } \\
\text { in the shade while taking a } \\
\text { water break, or visually } \\
\text { exploring the environment or } \\
\text { other children while resting }\end{array}$ & \\
\hline & Retreat & $\begin{array}{l}\text { where a child has removed themselves } \\
\text { to a small, controlled space; may } \\
\text { include the ability to look out and } \\
\text { watch others }\end{array}$ & $\begin{array}{l}\text { includes crawling into or } \\
\text { watching out from a fully or } \\
\text { semi-private fort, den or other } \\
\text { enclosed space }\end{array}$ & $\begin{array}{l}\text { exploratory-sensory or } \\
\text { restorative-onlooking: as in sitting } \\
\text { in a small fort peering out at the } \\
\text { environment or other } \\
\text { children nearby }\end{array}$ & \\
\hline & Reading & $\begin{array}{l}\text { when a child is reading or writing for } \\
\text { pleasure, or listening to others or music }\end{array}$ & $\begin{array}{l}\text { includes reading a book, } \\
\text { listening to another person } \\
\text { telling a story or reading to } \\
\text { them, or listening to music }\end{array}$ & $\begin{array}{l}\text { exploratory-sensory: as in } \\
\text { listening to a naturalist while } \\
\text { they exhibit a live animal }\end{array}$ & exploration \\
\hline & Onlooking & $\begin{array}{l}\text { where a child deliberately steps back } \\
\text { from nearby play for a period of } \\
\text { observation rather than interaction; } \\
\text { may just precede or follow play } \\
\text { with others }\end{array}$ & $\begin{array}{l}\text { when a child is sitting or } \\
\text { standing apart while clearly } \\
\text { watching others play or } \\
\text { interact nearby }\end{array}$ & $\begin{array}{l}\text { restorative-resting or } \\
\text { exploratory-sensory: as in sitting } \\
\text { on a log bench watching and } \\
\text { listening to other children } \\
\text { playing in a nearby setting }\end{array}$ & $\begin{array}{l}\text { onlooker behavior; } \\
\text { hovering }\end{array}$ \\
\hline
\end{tabular}


Table 4. Cont.

\begin{tabular}{|c|c|c|c|c|c|}
\hline Primary Play Type & Play Subtype & Description & Examples & $\begin{array}{l}\text { Common Intersections with } \\
\text { other Play Types }\end{array}$ & $\begin{array}{l}\text { Comparable Categories } \\
\text { from Other Typologies }\end{array}$ \\
\hline \multirow[t]{3}{*}{ Digital Play } & Device & $\begin{array}{l}\text { where child is playing with or on a } \\
\text { digital device with no interaction with } \\
\text { the real world/physical environment }\end{array}$ & $\begin{array}{l}\text { includes play games on a phone, tablet } \\
\text { or portable game device, or listening to } \\
\text { music through a device }\end{array}$ & $\begin{array}{l}\text { restorative-resting or } \\
\text { restorative-reading: as in sitting } \\
\text { on a park bench playing a game } \\
\text { on a phone, or laying on a } \\
\text { blanket listening to music }\end{array}$ & communication play \\
\hline & Augmented & $\begin{array}{l}\text { when a child is using a digital device to } \\
\text { mediate or augment their interaction } \\
\text { with the physical world }\end{array}$ & $\begin{array}{l}\text { includes playing Pokémon Go or other } \\
\text { augmented reality game, or using their } \\
\text { phone to read information transmitted } \\
\text { through QR codes in the environment }\end{array}$ & $\begin{array}{l}\text { play with rules: as in playing an } \\
\text { augmented reality game with } \\
\text { peers in the space }\end{array}$ & \\
\hline & Embedded & $\begin{array}{l}\text { when the child is interacting with } \\
\text { digital prompts or devices embedded } \\
\text { in the real world/physical environment } \\
\text { without a personal digital device }\end{array}$ & $\begin{array}{l}\text { includes activating digital sensors in the } \\
\text { environment to hear sounds or see light } \\
\text { displays, playing a digital instrument } \\
\text { embedded in the environment, playing } \\
\text { with an interactive digital screen in } \\
\text { the environment }\end{array}$ & $\begin{array}{l}\text { expressive-performance or play with } \\
\text { rules: as in playing musical } \\
\text { sounds via a digital instrumental } \\
\text { device embedded in the space or } \\
\text { playing a digitally-embedded } \\
\text { game with friends }\end{array}$ & \\
\hline \multirow[t]{6}{*}{ Non-Play } & Self-care & $\begin{array}{l}\text { when a child is engaged in an activity } \\
\text { meant to take care of themselves or } \\
\text { their appearance; can include helping a } \\
\text { friend or sibling to do these activities }\end{array}$ & $\begin{array}{l}\text { includes taking off socks and shoes, } \\
\text { tying shoelaces, tucking in shirt, or } \\
\text { cleaning hands }\end{array}$ & & transition \\
\hline & Nutrition & $\begin{array}{l}\text { when a child is taking a break to eat } \\
\text { or drink }\end{array}$ & $\begin{array}{l}\text { eating lunch or a snack, taking a drink } \\
\text { of water }\end{array}$ & & transition \\
\hline & Distress & $\begin{array}{l}\text { when a child is disengaged from play, } \\
\text { and exhibiting signs of distress }\end{array}$ & $\begin{array}{l}\text { crying, throwing a tantrum, throwing } \\
\text { objects in frustration }\end{array}$ & & anxious behaviors \\
\hline & Aggression & $\begin{array}{l}\text { refers to non-playful, agonistic } \\
\text { interactions with another child or adult }\end{array}$ & $\begin{array}{l}\text { includes hitting, kicking, grabbing, } \\
\text { pinching, scratching, threatening }\end{array}$ & & \\
\hline & Transition & $\begin{array}{l}\text { where the primary activity is } \\
\text { non-playful movement from one space } \\
\text { or point to another, and there is little to } \\
\text { no active engagement or exploration of } \\
\text { the environment }\end{array}$ & $\begin{array}{l}\text { includes walking or running in or out of } \\
\text { the play space, or from one play setting } \\
\text { to another }\end{array}$ & $\begin{array}{l}\text { exploratory-sensory: as in walking } \\
\text { to the bathroom, but also } \\
\text { actively visually exploring the } \\
\text { environment as they go }\end{array}$ & transition \\
\hline & Other & $\begin{array}{l}\text { other types of observed "non-play" } \\
\text { activities; can include "chores" or clean } \\
\text { up work, especially if directed by an } \\
\text { adult and not initiated by the child }\end{array}$ & $\begin{array}{l}\text { includes picking up litter and placing in } \\
\text { garbage bin, putting away play } \\
\text { materials or gathering belongings when } \\
\text { getting ready to leave the play space }\end{array}$ & & transition \\
\hline
\end{tabular}




\subsection{Exploratory Play}

This play type is used to describe playful interactions with the environment where the child is exploring or manipulating the properties of an object or the environment, either in a more sensory-based learning capacity or towards some child-established goal. Children are innately curious about their world and drawn to learning about it through interaction [2]. The degree of engagement and manipulation can vary from more passive, sensory-based interactions, such as rubbing a leaf or running their fingers through a pile of sand to experience their textures, to more active manipulation of the environment, like shoveling dirt into a pail, or to even more constructive activities where the child is actively building or forming something out of environmental elements, like a sand castle or a fort. It is through such exploratory engagements that children learn not only about the physical and spatial properties of their environment, but about their own capacity for manipulating objects or environments towards some intrinsic goal or problem [1,2,41]. The skills developed during exploratory play, such as sensory observation and an understanding of cause-and-effect relationships, are key to cognitive development; they can stimulate creative thinking, spatial reasoning, and problem solving, and are also considered central to math and science learning [2,8,35,42-45]. Several studies also suggest exploratory play with objects helps to lay the foundations for language development and literacy skills, particularly when combined with pretense [34]. The playful repetition of exploratory activities assists with the development of neural pathways in the brain which cement these movements and make them easier to recall in the future [1,2]. When it is valuable to understand the degree of engagement and level of environmental manipulation, exploratory play can be coded using the three subtypes-sensory, active, and constructive (See Table 4).

Exploratory play in the TOPO typology encompasses play activities that have been categorized elsewhere as sensory play, sensorimotor play, object play, mastery play, cause-and-effect play, construction or constructive play, and to some degree, creative play or deep play (See Table 4). It is important to note that this play type focuses primarily on children's interactions with elements within their environment, not with other people; social interactions are captured either through other play types or separately with a social interaction measure.

\subsection{Imaginative Play}

This play type is for activities which involve any element of pretense, role play, or imagination. This includes pretending that a stick is a cell phone or a wizard's wand, to taking on social roles such as a parent, chef, or bus driver, to more fantastical roles like commanding a spaceship or playing a super hero. Through imaginative or pretend play, children construct their own realities where they experiment with different roles, learn to solve problems, and in turn improve their mastery of their social and physical environments [21,46]. Children are inherently and universally drawn to creating and acting out pretend narratives, which has been shown to be "a key to emotional resilience and creativity" throughout the lifespan [2] (p. 87). Imaginative play is a way for children to safely experience and resolve social and moral situations, express their needs, develop empathy and trust, and act out potential solutions without negative consequences $[1,2,21,46]$. Imaginative play has also been significantly linked to the development of social, self-regulation, language and cognitive skills, as well as reading and writing capabilities $[1,3,21,34,47,48]$. Recent work is providing support for the notion that pretend play can increase children's creativity levels and contribute to the development of emotion regulation [49,50]. Outdoor environments, which tend to exhibit more environmental variation and place fewer limits on children's playful interactions, can be particularly conducive to cultivating children's curiosity and sparking imaginative play [8]. Imaginative play is often heavily reliant on the availability of loose or manipulable materials in the environment that can serve as props to the pretense [21], which may be more plentiful or varied in outdoor environments.

Imaginative play can be further divided into several subtypes-symbolic, sociodramatic, and fantasy activities (See Table 4). Imaginative-symbolic describes play where a child takes some real object in the environment as a substitute for a pretend object or animates it in some way, such as imagining a 
block of wood to be a running car or bringing a toy dinosaur or doll to life. Imaginative-sociodramatic play is where a child imitates a social, domestic, or interpersonal role that they could experience as adults, such as playing parents or "house", organizing or cooking a meal, or pretending to go to work. This form of play allows children to enter the world of adults, experiment with the social tools and roles of the culture, and safely try on different roles to understand their nature and appropriateness $[1,9]$. The "social scripts" which underlie many socio-dramatic scenarios promote not only social learning, but may indirectly promote reading comprehension and other forms of intellectual development [1] (p. 21). The third subtype, imaginative-fantasy, also describes role play but relates to scenarios that are not personal or domestic or likely to be experienced in real life; for example, when a child pretends to be a princess, wizard, a superhero, or becomes the dinosaur themselves. Role play where children integrate symbolic play with enacted narratives can be especially valuable during early childhood, supporting the development of emerging literacy and language skills [51,52]. Note that identifying the socio-dramatic and fantasy subtypes of imaginative play relies heavily on both contextual and verbal cues; while it may be obvious on the surface that the child is involved in some sort of pretend play, identifying the subtype often requires hearing the child's narrative about their activity as a "parent" or "chef", or observation of an associated environmental prop, such as a play oven or a superhero cape.

\subsection{Play with Rules}

This play type expands on previous play typologies' use of games with rules to more broadly capture any play activity or game by two or more children where there is some agreed-upon framework of rules governing the activity. Children naturally seek to make sense of their physical and social worlds, and so are inherently drawn to rules and rule-based play from a very young age [34]. This kind of play may often take the form of conventional games, such as hide-and-seek, capture-the-flag, or baseball, where there is a pre-established set of rules that tend to be universally understood by players. However, it also includes more organically developed play games and scenarios where children invent, negotiate, and continually modify the rules of play; for example, a group of children may collectively decide to take on superhero or villain personas and establish an elaborate set of rules dictating how and where the superheroes can chase and lock up villains. While this play is also imaginative, the key element being captured by this play type is the process of negotiating and abiding by a set of play parameters.

Burdette and Whitaker remind us that rule-based play is inherently social, as it always requires "solving some form of a social problem, such as deciding what to play, who can play, when to start, when to stop and the rules of engagement" [8] (p. 48). In fact, children can spend most of their play time and energy developing, negotiating, and modifying play rules with their peers [34]. Rule-based play provides children the opportunity to test and learn about social and cultural practices [1], including the value of taking turns and listening to the perspectives of others [34]. In working through dilemmas and conflicts with others, which often includes controlling their own impulses and behaviors, children build emotional skills and capabilities that are critical to successful social relations during childhood and later in life, such as cooperation, flexibility, empathy, and self-regulation $[3,8,21,34]$. Engagements where children negotiate and collectively problem solve with peers has also been shown to support language development [3].

Play with rules can be divided into two key subtypes-conventional and organic. Conventional activities cover common, universally understood rule-based games, such as hide-and-seek or soccer, where players are agreeing to play by the set rules but little negotiation is needed to establish the initial rules of play. Play with rules—organic is intended to capture those play scenarios that have been developed together by children, often from scratch, and which continue to evolve as play progresses. Conventional rule-based play can actually morph into the organic form when players decide to significantly alter the universal rules during the course of play, such as adding a fourth base in a baseball game, or requiring that players circle the bases by running backwards. Table 4 provides a more detailed description and examples of these subtypes. 


\subsection{Expressive Play}

This play type is used to characterize those play activities where some form of communication or expression is integral to the play activity. Children engage in many forms of expressive play, even from infancy. Very young children coo and babble, playing with sounds and vocalizations until, and even beyond the development of language abilities [1,9]. The interest in sounds, language play, and vocal performance evolves into singing songs, mimicry, telling rhymes, making up jokes, and reciting tongue twisters [1,21]. These expressive experiences have been linked to language development, and later, reading skills [1,9]. Children are also drawn to expression through other artistic and creative endeavors, such drawing, painting, sculpting, mark-making, as well as through musical, dance, and dramatic performances. Frost, Wortham, and Riefel suggest that school-age children particularly are "eager inventors and artists who demonstrate confidence and competence in their creative endeavors" [9] (p. 202). When they craft patterns in mud or paint pictures on paper, children are becoming aware that they can make something that is theirs alone and are developing an aesthetic appreciation for their environments [9]. Several alternative education programs, such as the Reggio Emilia school, believe that engaging in playful and artistic activities also helps a child to more deeply absorb, consolidate, and extend what they have learned from their observations and experiences $[9,53]$.

This play category is therefore intended to capture a range of expressive play activities and can be further divided into four subtypes-performance, artistic, language, and conversation. Expressive-performance captures playful activities where a child is intentionally performing some way, such as singing, dancing, juggling, or playing music explicitly for the enjoyment of others. Expressive-artistic is used when a child is manipulating the environment specifically for an artistic, creative, or aesthetic outcome, such as arranging leaves in a pattern, drawing spirals or pictures in the dirt or sand, or using something in the environment to make playful noises. The expressive-language subtype describes activities where a child is playing with words and vocal sounds, including making up rhymes, jokes or chants, storytelling, or playful vocalizing. Finally, expressive-conversation is intended to categorize play where the primary engagement is talking to or verbally interacting with other children but which does not involve any pretend or role play; for other forms of verbal communication taking place during or alongside play, we recommend using the separate Play Communication Typology measure (see Appendix A). Many of these expressive play activities are often seen concurrently with exploratory play or imaginative play activities. More details and examples can be found in Table 4 .

\subsection{Bio Play}

Children's experiences in nature are important, as they can be linked to positive health and wellness benefits, cognitive development, and emotional connections to nature [54]. Theory and research suggest that children's direct and unstructured encounters with wildlife are more developmentally significant than structured encounters mediated by adults [55]. Viewing animals in the wild, as compared to in captivity, can have longer lasting sensory impressions and contribute more to the development of an emotional affinity toward animals [56]. This strengthened impact might be explained by the knowledge that stronger emotions occurring at the time of an experience can lead to more vivid and long-lasting memories [57]. Natural interactions may be more exciting and thrilling for children than controlled exposures, and therefore, may denote a more significant opportunity to shape a child's lasting memories. Childhood play in nature can also lead to lifelong preferences for natural experiences and pro-environmental behaviors [58,59].

In order to be able to capture these important interactions with nature, we have added a new category of outdoor play called bio play (drawing on the Greek root for "life"). This category can be used to record those significant moments when a child has focused their attention on a living plant or animal in the playscape. Although these experiences might also be recorded in another category, such as exploratory play, the significance of these natural experiences is profound enough to warrant capturing these interactions through a distinct play type. 
Educators in the field of sustainable development believe that children can benefit from three aspects of environmental experience; the opportunity to be educated about the environment, to experience the natural environment, and to act for the environment [60]. Several subtypes allow for a further level of distinction among these environment interactions during outdoor play (see Table 4). The bio-plants combination is used to categorize playful interactions with living plants, from grass or flowers to shrubs and large trees. Bio-wildlife can be used to identify interactions with animals, from small bugs, butterflies and worms, to larger wildlife species like birds, fish, and mammals. A third subtype, bio-care, is designed to identify children's play-based stewardship behaviors where the child acts with concern for the health of the environment, or demonstrates an appreciation or understanding of the value of nature and natural resources. This may include activities such as recycling waste, watering a plant, "planting" an acorn, or "rescuing" a caterpillar. Overall, the bio play category is useful for capturing the range of valuable interactions with living things which natural playgrounds can offer.

\subsection{Restorative Play}

The TOPO includes another new category of play referred to as restorative play. This category contains the subtypes resting, retreat, reading, and onlooking. Observations of play demonstrate that there are times when children will retreat from a play episode or hesitate to join other children engaged in play. There are many possible motives, including wanting to watch the other children play, avoiding conflict, or taking a break from a play cycle that required a sustained focus of attention. According to Kaplan, nature may contribute to attention restoration [61], which may play a significant role in the benefit of the outdoor play experiences for children. An outdoor play typology then, should include the ability to identify these and other restorative behaviors.

The restorative nature of resting and reading behaviors are fairly self-explanatory. The subtype retreat, however, requires more explanation; during a play cycle, children will often temporarily pull back from interactive play or seek out a small, safe place to take respite from more active or social play activities. Sobel and Hart have both written about children's widespread use of "special places"-finding or building small-scale, somewhat enclosed spaces (e.g., dens, forts, treehouses, playhouses, or even cardboard boxes) where they often go to enjoy time alone or play with a friend $[62,63]$. Children have a tremendous need for both physical and psychological privacy with few opportunities to achieve it; in these "away" places, children explore a sense of separateness, as well as exercise a measure of control over their environment and interactions [63-65]. A recent study from Australia notes that over $85 \%$ of 8 to 9-year-old children expressed a high level of enjoyment from "hiding" outdoors, and $70 \%$ of these children enjoy using their recess time for resting and relaxing outdoors [66]. In another study, over a quarter of children sampled (aged 8-13 years) reported that they went to their favorite places after emotionally challenging events and for cognitive restoration and relaxation [67]. School children have been found to retreat from larger spaces in school yards, finding places on the edges which offered the freedom to play away from the crowds [68]. Children and youth often seek out and benefit from opportunities to retreat or rest from their daily experiences as part of their play cycle.

The onlooking subtype also describes a form of restorative play. Parten described a category of social play as onlooker [28], which has been used by researchers to describe children who may exhibit anxiety or reticent behavior which may prevent them from interacting with others [69], and which appears in the typologies of Frost and Rubin (see Table 1). It is common for children to demonstrate reticent behavior in which they hover on the edge, observing other players in a social circle; however, different forms of solitude may indicate different "meanings" for each child, depending on age, personality, and circumstances [69] (p. 135). Although this behavior is often thought to identify children who are shy and not as socially advanced, it is clear from the Coplan et al. study [69] that most children engage in some form of observer behavior during play group experiences. Largely a neglected element of play to date, it can be useful to understand how children use the environment for periods of restoration during a play cycle. 


\subsection{Digital Play}

Any play typology developed in the 21st century must acknowledge the growing prevalence of play with and through digital devices, even in outdoor environments. Advancements in digital technology, particularly in the increased development and accessibility of portable digital devices for game play, such as smart phones, tablets, and game devices, has led digital play to comprise an increasingly large part of many children's play activities [70,71]. While research related to digital play is still in its infancy, reviews of children's play with computer or video games shows that there can be positive developmental outcomes, including knowledge acquisition, as well as cognitive and perceptual advances [34].

Not only is it becoming much more common to see children playing on some sort of digital device while in an outdoor play space, but digital technologies are also being embedded more and more in some form within outdoor play spaces themselves to provide novel ways to engage children in playful activities. For example, in the Darling Quarter Precinct in Sydney, Australia, an interactive digital art platform was installed in a large green space that allows visitors to use a touchscreen kiosk to digitally "paint" designs in light or else play over-scaled arcade games on the facades of the buildings surrounding the park. On a smaller scale, some outdoor play spaces are installing small digital sensors that trigger musical sounds when a visitor passes by, allowing players to compose their own "songs" by moving through the space. While still usually comprising just a small portion of observed outdoor play activities, we felt that a new outdoor play typology must include some ability to acknowledge and capture the growing popularity of digital play. Subtypes developed within this category help to distinguish whether the play is happening primarily on a device with no interaction with the physical environment (digital-device), or when a portable digital device is being used to create a digital-physical hybrid environment, such as through augmented reality games like Pokémon Go where the digital elements are overlaid on the physical environment (digital-augmented). A third subtype-digital-embedded — captures play that engages digital elements which have been integrated with the physical play environment itself through the use of sensors or interactive digital platforms. See Table 4 for more details and examples.

\subsection{Non-Play}

This final category is intended as a way to code behaviors which take place during an overall outdoor play cycle, but which are not considered to be "play". Non-play activities include scenarios where a child is stopping to take care of themselves in some way, such as tying a shoelace, cleaning their hands, or taking a snack break. This category can also be used when the primary behavior observed is one of distress or aggression, where the child is disengaged entirely from play and either behaving in a distressed manner, such as crying or throwing a tantrum, or acting in an antagonistic way toward another child or adult, such as hitting, kicking, grabbing, or threatening them. Non-play can also be used to denote when a child is simply in the process of moving from one location to another, such as heading to the bathroom or moving to another play setting. This transition can sometimes be accompanied by some playful behavior, such as actively scanning the environment for birds or bugs as they move; in such a case, the behavior could also be categorized by another play type, such as exploratory-sensory. Finally, this category can be used to capture any other non-play activities observed, such as packing up belongings or some adult-directed tasks. These activities can be differentiated through the six subtypes-self-care, nutrition, distress, aggression, transition, and other (see Table 4).

\section{Key Lessons and Innovations}

The development and repeated testing of the TOPO yielded a few insights which are key to more effective use of the proposed outdoor play typology as an observation tool. The TOPO is intended to more effectively capture the diverse types of outdoor play that may be observed in a given setting and across a broad range of ages, and does not privilege one aspect of play as better or more developmentally 
advanced than another. To reflect this goal, we propose two particular innovations-eschewing any hierarchical framework of play types, and the use of up to two play types for each play observation to more fully and reliably characterize children's outdoor play.

Many of the play typologies which have been used to study children's play to date (e.g., Rubin's Play Observation Scale, Smilansky's cognitive play typology, or van Schnijdel et al.'s Exploratory Behavior Scale) were actually developed as scale tools which, by their nature, necessarily set up a hierarchy of play types, ranking play types relative to one another. Depending on the goal of the scale, such as capturing evidence of play that is considered to reflect a higher level of cognitive or social development, the developers privilege certain play types above others. Observers are directed to select the single play type which ranks higher on the scale. For example, if an observer witnessed a group of children playing an elaborate chasing game they collectively invented, during which they each also take on the role of wizards, by both Rubin's POS and Smilansky's play scales, the play episode could be categorized as both a game with rules and dramatic play. Since the observer can only choose one play type, they are directed to choose games with rules, as it is considered more cognitively and socially mature behavior by the developers. While such a protocol helps to improve reliability across different observers or when the play activity exhibits characteristics of more than one play type, these scale tools do not describe the full nature of the play activity.

Frost [21] reminds us that children's play activities are often complex in nature, and it can be difficult to untangle an observed play episode and distill it into a single play type. In his own work, for example, Frost found that what he calls functional or exercise play was often intricately woven with dramatic or constructive activities [21]. Some studies have dealt with this issue by adding a mixed play category to be able to account for situations where the play reflects several of the other play types without one being dominant [19]. After years of field observations of play, the authors too continually struggled to accurately categorize play activities using a single play type, and in consequence, reported low levels of inter-rater reliability across multiple observers. When the goal is to capture the complex essence of children's play activities or understand how well an environment supports a diverse range of play activities, establishing any kind of hierarchy within the play types is counterproductive. We also recognize that children do not necessarily develop physical, social, or cognitive skills along fixed, linear paths as once believed [9], and so a given play activity may not accurately reflect the developmental level or capacities of the child. Inclusive play advocates would also warn against developing a typology which values some play types as better or more advanced if they only reflect the developmental progression of fully able-bodied or neuro-typical children.

Through the development and testing of this new typology and tool, it became clear that unless the goal of a study is to record evidence of a specific type of play or interaction, to reliably and fully capture the nature of children's outdoor play behaviors, the observation protocol must allow for a minimum of two different play types to be associated with a single play episode. The ability to record more than one play type largely negates the need for any hierarchy within the typology. It is also in the combination of the two play types that the more holistic spirit of the play is revealed. This protocol was tested in phases 3 and 5; when observers were encouraged to code up to two play types, inter-rater agreement increased substantially, and the combination of play types more faithfully reflected the play episode. The addition of a third play type did not significantly improve either the understanding of the play episode or the inter-rater reliability. Most third play types recorded related to the type of communication that was supplementing the play; when this verbal communication was removed to a separate measure using the Play Communication Typology (see Appendix A), the addition of a third play type was deemed largely unnecessary to the provision of a rich picture of the play episode.

\section{Using the TOPO Tool}

The TOPO tool can be effectively utilized for both person-based (i.e., extended observation over time of individual children) or place-based (i.e., systematic recording of the play behaviors of a range of children in a single setting) observations. When the goal is to assess the quality of the environment for 
supporting a diverse range of play types, a place-based protocol is more effective. For these studies we recommend a systematic scanning protocol where an individual child is observed for approximately 15 seconds, and then up to two play types (and subtypes if possible) which best capture the essence of the play episode are selected. When a play activity could be categorized under more than two play categories, observers are encouraged to choose the primary play types which best reflect the spirit of the play behavior, and to privilege all play categories over non-play types. See Appendix B for a sample protocol and template for using the TOPO for field observations.

Analyses of both outdoor play behaviors and environments can also be expanded by using the TOPO in combination with other measures designed to capture elements of play activities, depending on the goals of the study, such as: peer interaction, play communication, activity intensity, level of risk, use of loose parts, and wildlife interaction. Ideally, outdoor play activities are child-initiated and led, but some forms of play or some types of play environments may involve greater levels of adult direction or instruction; it can be helpful to use a supplemental measure to capture the level and form of adult interaction related to play activities. For a detailed field observation and behavior mapping protocol which combines outdoor play types with additional select measures to develop a comprehensive picture of children's outdoor play activities, see this article by Cox, Loebach, and Little [72].

While the TOPO is primarily designed as a field observation tool, the embedded typology could also be used as a valuable framework for diverse analyses of outdoor play. The typology is also still highly suitable for observing children's play in indoor settings, and in fact may add additional value due to the inclusion of newly defined play types. Unlike earlier indoor play type scales, the emerging categories of bio play and digital play in the TOPO can now acknowledge these increasingly common interactions indoors, such as school children taking care of classroom pets or plants, or children playing games on phones or tablets. While the proportion or intensity of some play types, such as physical play, may differ from outdoor settings, the TOPO can still effectively capture the range of play taking place (or not) in the indoor play spaces of schools, child care centers, community recreation facilities, and other indoor environments. Unlike previous play type tools, the ability to utilize the TOPO for both indoor and outdoor play also now allows for direct comparisons of play behaviors taking place in each type of setting, highlighting the differences in the support for play provided by both types of environments. The inability to use a single unmodified tool to effectively assess and compare both indoor and outdoor play behavior has been a significant gap in the field to date.

\section{Collapsed and Expanded Versions}

Based on our own field experience and feedback from expert reviewers, we know that it can sometimes be difficult to utilize a large or complex observation tool under field conditions. Time is usually of the essence, as researchers aim to capture as many real-time play episodes as possible. A more complex tool can also require additional training time to minimize inconsistency between observers. However, some research studies or environmental evaluations require or desire a finer level of distinction between play behaviors. The TOPO tool has therefore been developed so that it can be utilized in either a collapsed or expanded version; researchers can choose which version best supports their research or evaluation goals, or which aligns with the time and resources available for field observations.

The collapsed version, TOPO-9, only utilizes the nine primary play types to categorize play activities. This version may be better suited to studies attempting to collect substantial data in the field or which have a limited amount of time for observations or training. The collapsed version might also better serve observations on larger or more complex study sites, when the play settings are large, in busy areas, or where it is difficult for an observer to get close enough to hear and see finer details of the play episode; the ability to make distinctions between subtypes often requires additional contextual clues that may only be apparent when the child can be heard or viewed up close. For example, a child pushing a large block through a pile of dirt can be coded from afar, as exploratory-active and physical-fine; the observer must be closer to hear them making car engine noises to know that they are imagining the 
block to be a car, now allowing the play episode to also be coded as imaginative-symbolic. Observers may in fact need to use the collapsed version when the study site does not allow for close, unobtrusive observation. For cases when only a high-level understanding of the diversity of play activities taking place in an environment is also needed, the TOPO-9 version would be sufficient.

The expanded version of the tool, TOPO-32, draws on the 32 associated subtypes to designate primary-subtype combinations for each observed play episode. This expanded tool allows observers to capture a much more detailed and nuanced picture of play behaviors taking place or being supported in a given environment. While requiring a bit more time for training and field collection, this version is well-suited to play environments that have several smaller-scale play settings or which allow for close but unobtrusive observation. The TOPO-32 provides a richer dataset which can be used to more thoroughly explore differences in play behavior by age, group size, gender, or other child characteristics, as well as reveal more details of how environmental features and conditions are supporting or limiting play.

While observation should be as unobtrusive as possible when using either version of the tool, the position of the observer should be close enough to see and hear details of the child's play, especially when using the expanded TOPO-32. As Pellegrini suggests, to more fully understand children's activities "observers might attend more closely to what children actually say and do during ... play" [73] (pp. 571-572). The details which emerge through close observation are key to accurate and effective behavior coding.

\section{Conclusions}

This paper outlined the development and use of a new observational framework for studying child-initiated outdoor play, as well as the environments which support diverse play opportunities for children. Testing of the Tool for Observing Play Outdoors demonstrated qualitative validity, as well as a high level of reliability across trained observers. While our own primary interest was in preparing a tool which could effectively evaluate the play environment itself, the TOPO can easily be used for a range of studies of children's outdoor and indoor play behaviors, as well as child health and development, particularly when paired with other complementary measures of play and interaction. This new tool represents a significant advance in the ability to fully and effectively capture children's unique outdoor play behaviors, and to evaluate the quality of the environments which afford them. Use of this tool to study and plan outdoor play environments can help us provide more diverse, high-quality play settings that will support the healthy development of children across the spectrum.

Next steps in the development of the tool will include widespread testing of the TOPO in a diverse range of outdoor play spaces, from traditional outdoor playgrounds to children's gardens, play trails, and nature play spaces. Observations using the TOPO will be triangulated with data from surveys and/or interviews with children, parents, and staff members (as applicable) to confirm that the tool is effectively and accurately capturing children's outdoor play activities. This testing will further strengthen the validity and reliability of the tool, and confirm its utility for observations in a wide range of outdoor play environments.

The authors are also developing additional materials and resources to support TOPO training for observers, as well as its use in diverse environmental settings. We encourage play researchers and practitioners to contact us for more information related to training in or use of the TOPO.

Author Contributions: Both authors were involved in all aspects of the development and testing of the tool, as well as the preparation of the manuscript. Conceptualization: J.L. and A.C.; Data Collection \& Analysis: J.L. and A.C.; Testing and Validation: J.L. and A.C.; Writing-Draft Preparation, Review and Editing: J.L. and A.C. All authors have read and agreed to the published version of the manuscript.

Funding: This research received no external funding.

Acknowledgments: No funding was solicited or received in support of this project. The authors would like to thank all those who contributed to the review of the tool including: Vicki Carr, Theresa Casey, Ashley Miller Helmholdt, Jane Hewes, Ingrid Kanics, Mary Ann Rintoul, Claude Stephens, Jenny Sumrell, Agnes van den Berg, Phil Waters, and Helen Woolley. 
Conflicts of Interest: The authors declare no conflict of interest.

\section{Appendix A. The Play Communication Typology [PCT]}

This separate but complementary typology to the Tool for Observing Play Outdoors (TOPO) is designed to capture communication taking place within or around a play episode where there is communication. The types of Play Communication are outlined below:

1. Play: When the child is communicating with other children (or even an adult) about or as part of the play event they are mutually engaged in, or else to sustain or expand the play event. Examples: "Let's pretend we are mommies and daddies and we live in this 'house'" or "You know what else we should do to this sandcastle? Add a fence and a moat around the outside".

2. Environment: When the child is talking to an adult or peer about the environment they are in, such as pointing out elements in the environment (e.g., "Look at this flower!"), or noticing how they can interact with it (e.g., "Look what happens when I pour water into the sand").

3. Peer-Social: When the child is talking to one or more children for social enjoyment, where the discussion is unrelated to the play activity. Examples: What's your favorite subject at school right now? or "Did you see the new Avengers movie?"

4. Adult-Social: When the child is talking to one or more adults, such as a parent, teacher or camp counselor, for social enjoyment, where the discussion is unrelated to the play activity.

5. Cowabunga!: When a child makes a vocal or bodily expression of thrill, surprise, or excitement (e.g., "Cowabunga!", “Woo-Hoo!", or “Wow, that was sooo fast!"); this communication often relates to risky or challenging play. [Note: Cowabunga is a pop culture term used by a range of TV characters from Howdy Doody to the Teenage Mutant Ninja Turtles to express joy, thrill, and enthusiasm. We find it an excellent descriptor of these otherwise hard-to-describe communications].

6. Wayfinding: When the child is talking to a peer or adult specifically about finding their way around the environment they are in (particularly if it is a large space or compound).

7. Instructive: When the child is listening to or communicating within an adult-led structured activity, instruction, or lesson; could include being read to by an adult or when an adult is giving a warning or issuing restrictions to the child. It can also include when a child is issuing instructions or restrictions to another child (e.g., "Go tell Dad we are ready for lunch"); however, if it is within the context of a play activity (e.g., "Bring that log over here to add to the fort") it would be better coded under the play category.

8. Care: When the child is communicating in order to care for or warn a peer or family member (e.g., "Be careful!" or "Look out, your shoelace is undone").

9. Permission-Seeking: Child is asking permission from a peer or adult to engage in a given activity or to use a given play object or environment.

10. Self-talk: When the child is talking to themselves; this self-talk can be imaginative in nature or can include when a child is singing to themselves in a way that is not meant to be a performance for others. (Communication as part of a performance would be better coded under the play category).

11. Conflict: When the communication centers on an altercation or conflict between two or more children.

\section{Appendix B. Recommended Practices for Using the TOPO for Field Observations of Outdoor Play}

For additional information specific to Behavior Mapping, see also: Cox, A.; Loebach, J.; Little, S. Understanding the Nature Play Milieu: Using Behavior Mapping to Investigate Children's Activities in Outdoor Play Spaces. Youth Environ., 2018, 28, 232-261. https://doi.org/10.7721/chilyoutenvi.28.2.0232

\section{Overall Considerations}

- Determine if the collapsed or expanded version of the TOPO is preferred for project goals, keeping in mind the expanded version will require more in-depth training for observers. 
- Determine the type of observational approach best suited to project goals: person-based (i.e., extended observation over time of individual children) or place-based (i.e., systematic recording of the play behaviors of a range of children in a single setting).

\section{Site Considerations}

- Determine the number of observers needed and ensure that adequate training in the TOPO protocol has been conducted. Larger sites will need more observers in order to capture peak activity use in all zones, and to collect an adequate amount of observations.

- Delineate smaller observation zones and vantage points within large sites where observers can be unobtrusive yet close enough to hear and see significant contextual clues from children's play activities and interactions, particularly for the expanded version of the tool.

\section{Data Collection Preparation}

- Determine all data that will be collected and prepare forms for data collection. Observers may wish to pair the TOPO with other measures such as: child demographic characteristics, play communication types, physical activity levels, environmental interactions, etc.

- Data may be collected on paper or via a portable digital device. Digital options are recommended as many software programs can be used to develop forms with pre-established pull-down menus which will increase speed and accuracy in field data entry. See the attached sample templates for paper-based collection of play observations using either the collapsed TOPO-9 or the expanded TOPO-32, or for tips for organizing digital forms.

- If play episode data are also to be mapped, detailed site maps will need to be prepared for field data collection (digital or paper). See Cox et al. (2018) for more recommendations.

\section{Systematic Data Collection}

- Determine the amount of time researchers will observe each child or play episode. For place-based approaches we suggest observing each child for approximately 15 seconds before establishing and recording the play types. This allows observers to capture the essence of the overall play episode more accurately. For person-centered approaches, overall observation times of a single child may be longer, but we recommend breaking the observations into 15 second play episodes, recording the one or two play types that best characterize each episode.

- For each play episode, observers should aim to record two play types (with subtypes if using the expanded version) that best represent the observed play. Recording two play types provides a richer and more accurate picture of the play activity, but also tends to increase the reliability of the data collected.

- It is important to systematically collect data within each designated observation zone. For a place-based approach, start by determining how long to allow for scans of each zone (See Cox et al. (2018) for more details on scanning observation zones). Then choose a vantage point from where you can observe the entire zone, and then systematically scan the area (clockwise or counter-clockwise), stopping to record data when you visually encounter play activity. After those data are recorded, continue scanning in the same direction until you encounter another play event, continuing until the end of the designated time period. For person-centered data collection where you may be observing a single child over time, decide on a time-sampling protocol, that is, how often and for how long each child's behavior will be observed.

- To ensure a high level of inter-rater agreement when using multiple coders, observers should aim to conduct reliability rounds for $5-10 \%$ of the total number observations. During reliability rounds, all observers independently code the same play behaviors to compare levels of agreement; Kappa analysis can then be conducted to compare the reliability of inter-rater observations across the full dataset. 
See Tables A1 and A2 for sample templates for both the TOPO-9 and TOPO-32 versions of the tool.

Table A1. Sample Template for TOPO-9 (Collapsed Version).

\begin{tabular}{|c|c|c|c|c|}
\hline \multicolumn{5}{|c|}{ Sample Template for TOPO-9 } \\
\hline Play Type Codes: & $\begin{array}{l}\text { 1-Physical play } \\
\text { 2-Exploratory play } \\
\text { 3-Imaginative }\end{array}$ & $\begin{array}{l}\text { 4-Play with Rules } \\
\text { 5-Bio play } \\
\text { 6-Expressive play }\end{array}$ & $\begin{array}{l}\text { 7-Restorative play } \\
\text { 8-Digital play } \\
\text { 9-Non play }\end{array}$ & \\
\hline Play Event No. & Relevant child info * & Play Type 1 Code & Play Type 2 Code ** & $\begin{array}{l}\text { Additional play } \\
\text { characteristics }\end{array}$ \\
\hline & & & & \\
\hline & & & & \\
\hline & & & & \\
\hline & & & & \\
\hline & & & & \\
\hline & & & & \\
\hline & & & & \\
\hline & & & & \\
\hline & & & & \\
\hline & & & & \\
\hline & & & & \\
\hline & & & & \\
\hline & & & & \\
\hline & & & & \\
\hline & & & & \\
\hline & & & & \\
\hline & & & & \\
\hline & & & & \\
\hline & & & & \\
\hline & & & & \\
\hline & & & & \\
\hline & & & & \\
\hline & & & & \\
\hline & & & & \\
\hline & & & & \\
\hline & & & & \\
\hline & & & & \\
\hline & & & & \\
\hline & & & & \\
\hline & & & & \\
\hline & & & & \\
\hline & & & & \\
\hline & & & & \\
\hline & & & & \\
\hline & & & & \\
\hline & & & & \\
\hline & & & & \\
\hline & & & & \\
\hline & & & & \\
\hline & & & & \\
\hline & & & & \\
\hline & & & & \\
\hline & & & & \\
\hline & & & & \\
\hline
\end{tabular}

* Recommend inserting additional columns for relevant child info (e.g., age/age range; gender.). ${ }^{* *}$ Recording a second play type is optional but recommended. ${ }^{* * *}$ Recommend pairing the TOPO with other scales or measures to capture additional characteristics of the play event. (e.g., social interaction, play communication, physical activity level, environmental interaction, level of risk, etc.). 
Table A2. Sample Template for TOPO-32 (Expanded Version).

\begin{tabular}{|c|c|c|c|c|}
\hline \multicolumn{5}{|c|}{ Sample Template for TOPO-32 } \\
\hline \multicolumn{5}{|l|}{ Play Type Codes: } \\
\hline Physical play & Imaginative play & Bio Play & Restorative play & Non play \\
\hline $1 \mathrm{~A}-$ Gross motor & 3A-Symbolic & 5A-Plants & 7A-Resting & 9A-Self-care \\
\hline 1B-Fine motor & 3B-Sociodramatic & 5B-Wildlife & 7B-Retreat & 9B-Nutrition \\
\hline 1C-Vestibular & 3C-Fantasy & $5 \mathrm{C}$-Care & 7C-Reading & 9C-Distress \\
\hline 1D-Rough \& & & & & \\
\hline Tumble & & & 7D—Onlooking & $\begin{array}{l}\text { 9D-Aggression } \\
\text { 9E-Transition }\end{array}$ \\
\hline Exploratory play & Play with Rules & Expressive play & Digital Play & 9F-Other \\
\hline 2A-Sensory & 4A-Organic & 6A-Performance & 8A-Device & \\
\hline 2B-Active & 4B-Conventional & 6B-Artistic & 8B-Augmented & \\
\hline 2C-Constructive & & $\begin{array}{l}\text { 6C-Language } \\
\text { 6D-Conversation }\end{array}$ & 8C-Embedded & \\
\hline
\end{tabular}

\begin{tabular}{|c|c|c|c|c|}
\hline Play Event No. & Relevant child info * & Play Type 1 Code & Play Type 2 Code $* *$ & $\begin{array}{l}\text { Additional play } \\
\text { characteristics }\end{array}$ \\
\hline & & & & \\
\hline & & & & \\
\hline & & & & \\
\hline & & & & \\
\hline & & & & \\
\hline & & & & \\
\hline & & & & \\
\hline & & & & \\
\hline & & & & \\
\hline & & & & \\
\hline & & & & \\
\hline & & & & \\
\hline & & & & \\
\hline & & & & \\
\hline & & & & \\
\hline & & & & \\
\hline & & & & \\
\hline & & & & \\
\hline & & & & \\
\hline & & & & \\
\hline & & & & \\
\hline & & & & \\
\hline & & & & \\
\hline & & & & \\
\hline & & & & \\
\hline & & & & \\
\hline & & & & \\
\hline & & & & \\
\hline & & & & \\
\hline & & & & \\
\hline & & & & \\
\hline & & & & \\
\hline & & & & \\
\hline & & & & \\
\hline & & & & \\
\hline & & & & \\
\hline & & & & \\
\hline & & & & \\
\hline
\end{tabular}

* Recommend inserting additional columns for relevant child info (e.g., age/age range; gender.). ${ }^{* *}$ Recording a second play type is optional but recommended. ${ }^{* * *}$ Recommend pairing the TOPO with other scales or measures to capture additional characteristics of the play event. (e.g., social interaction, play communication, physical activity level, environmental interaction, level of risk, etc.). 


\section{References}

1. Athey, I. Contributions of Play to Development. In Child's Play: Developmental and Applied; Yawkey, T., Pellegrini, A., Eds.; L. Erlbaum Associates: Mahwah, NJ, USA, 1984.

2. Brown, S. Play: How It Shapes the Brain, Opens the Imagination, and Invigorates the Soul; Penguin Group: New York, NY, USA, 2009.

3. Yogman, M.; Garner, A.; Hutchinson, J.; Hirsh-Pasek, K.; Golinkoff, R.M.; Baum, R.; Gambon, T.; Lavin, A.; Mattson, G.; Wissow, L. The Power of Play: A Pediatric Role in Enhancing Development in Young Children. Pediatrics 2018, 142. [CrossRef] [PubMed]

4. Milteer, R.M.; Ginsburg, K.R. The Importance of Play in Promoting Healthy Child Development and Maintaining Strong Parent-Child Bond: Focus on Children in Poverty. Pediatrics 2012, 129, e204-e213. [CrossRef] [PubMed]

5. Ginsburg, K.R.; The Committee on Communications and the Committee on Psychosocial Aspects of Child and Family Health. The Importance of Play in Promoting Healthy Child Development. Pediatrics 2007, 119, 182-188. [CrossRef] [PubMed]

6. Herrington, S.; Brussoni, M. Beyond Physical Activity: The Importance of Play and Nature-Based Play Spaces for Children's Health and Development. Curr. Obes. Rep. 2015, 4, 477-483. [CrossRef] [PubMed]

7. Glenn, N.M.; Knight, C.J.; Holt, N.L.; Spence, J.C. Meanings of Play among Children. Childhood 2013, 20, 185-199. [CrossRef]

8. Burdette, H.L.; Whitaker, R.C. A National Study of Neighborhood Safety, Outdoor Play, Television Viewing, and Obesity in Preschool Children. Pediatrics 2005, 116, 657-662. [CrossRef]

9. Frost, J.L.; Wortham, S.C.; Reifel, S. Play and Child Development, 4th ed.; Pearson Education, Inc.: Upper Saddle River, NJ, USA, 2012.

10. Wilson, R. Nature and Young Children: Encouraging Creative Play and Learning in Natural Environments, 2nd ed.; Routledge: London, UK, 2012.

11. Woolley, H. Watch This Space! Designing for Children's Play in Public Open Spaces. Geogr. Compass 2008, 2, 495-512. [CrossRef]

12. Luchs, A.; Fikus, M. A Comparative Study of Active Play on Differently Designed Playgrounds. J. Adventure Educ. Outdoor Learn. 2013, 13, 206-222. [CrossRef]

13. Fjørtoft, I. Landscape as Playscape: The Effects of Natural Environments on Children's Play and Motor Development. Child. Youth Environ. 2004, 14, 21-44.

14. Brussoni, M.; Ishikawa, T.; Brunelle, S.; Herrington, S. Landscapes for Play: Effects of an Intervention to Promote Nature-Based Risky Play in Early Childhood Centres. J. Environ. Psychol. 2017, 54, 139-150. [CrossRef]

15. Wells, N.M.; Evans, G.W. Nearby Nature: A Buffer of Life Stress Among Rural Children. Environ. Behav. 2003, 35, 311-330. [CrossRef]

16. Gilliland, J.A. Children and Nature: A Systematic Review; Lawson Foundation: Toronto, ON, Canada, 2017.

17. Hanski, I.; Von Hertzen, L.; Fyhrquist, N.; Koskinen, K.; Torppa, K.; Laatikainen, T.; Karisola, P.; Auvinen, P.; Paulin, L.; Mäkelä, M.J.; et al. Environmental Biodiversity, Human Microbiota, and Allergy Are Interrelated. Proc. Natl. Acad. Sci. USA 2012, 109, 8334-8339. [CrossRef] [PubMed]

18. Dyment, J.; O'Connell, T.S. The Impact of Playground Design on Play Choices and Behaviors of Pre-School Children. Child. Geogr. 2013, 11, 263-280. [CrossRef]

19. Storli, R.; Hansen Sandseter, E.B. Children's Play, Well-Being and Involvement: How Children Play Indoors and Outdoors in Norwegian Early Childhood Education and Care Institutions. Int. J. Play. 2019, 8, 65-78. [CrossRef]

20. Cox, A. Shared-Use Pathways Located in Natural Settings within the Urban Context: A Multiple Case Study Exploring How Design Affects Use by Children; North Carolina State University: Raleigh, NC, USA, 2013.

21. Frost, J.L. Play and Playscapes: Instructor's Guide; Delmar Publishers: Albany, NY, USA, 1992.

22. Hughes, B. A Playworker's Taxonomy of Play Types, 1st ed.; PLAYLINK: London, UK, 1996.

23. Hughes, B.; Melville, S. A Playworker's Taxonomy of Play Types, 2nd ed.; PLAYLINK: London, UK, 2002.

24. Rubin, K.H. The Play Observation Scale; University of Waterloo: Waterloo, ON, Canada, 1989. [CrossRef]

25. Rubin, K.H. The Play Observation Scale (POS)—Revised; University of Maryland: College Park, MD, USA, 2001. [CrossRef] 
26. Rubin, K.H. The Play Observation Scale (POS)—Revised; University of Maryland: College Park, MD, USA, 2008.

27. Piaget, J. Play, Dreams, and Imitation in Childhood; W.W. Norton: New York, NY, USA, 1962.

28. Parten, M.B. Social Participation among Preschool Children. J. Abnorm. Psychol. 1932, 27, $243-269$.

29. Hughes, B. Evolutionary Playwork: Reflective Analytic Practice; Routledge: London, UK, 2012.

30. Smilansky, S. The Effects of Sociodramatic Play on Disadvantaged Preschool Children; John Wiley \& Sons: New York, NY, USA, 1968.

31. Carlson, F. Rough and Tumble Play 101. Exchange 2009, 26, 70-73.

32. Brussoni, M.; Gibbons, R.; Gray, C.; Ishikawa, T.; Sandseter, E.B.H.; Bienenstock, A.; Chabot, G.; Fuselli, P.; Herrington, S.; Janssen, I.; et al. What Is the Relationship between Risky Outdoor Play and Health in Children? A Systematic Review. Int. J. Environ. Res. Public Health 2015, 12, 6423-6454. [CrossRef]

33. Bjorklund, D.F.; Brown, R.D. Physical Play and Cognitive Development: Integrating Activity, Cognition, and Education. Child Dev. 1998, 69, 604-606. [CrossRef]

34. Whitebread, D.; Neale, D.; Jensen, H.; Liu, C.; Solis, S.L.; Hopkins, E.; Hirsh-Pasek, K.; Zosh, J.M. The Role of Play in Children's Development: A Review of the Evidence; LEGO Foundation: Billund, Denmark, 2017.

35. Van Schijndel, T.J.P.; Franse, R.K.; Raijmakers, M.E.J. The Exploratory Behavior Scale: Assessing Young Visitors' Hands-on Behavior in Science Museums. Sci. Educ. 2010, 94, 794-809. [CrossRef]

36. Landis, J.R.; Koch, G.G. The Measurement of Observer Agreement for Categorical Data. Biometrics 1977, 33, 159. [CrossRef]

37. Cresswell, J.W.; Poth, C.N. Qualititative Inquiry E Research Design: Choosing Among Five Approaches, 4th ed.; Sage Publications Inc: Thousand Oaks, CA, USA, 2018.

38. Rine, R.M.; Wiener-Vacher, S. Evaluation and Treatment of Vestibular Dysfunction in Children. NeuroRehabilitation 2013, 32, 507-518. [CrossRef] [PubMed]

39. Wiener-Vacher, S.R.; Hamilton, D.A.; Wiener, S.I. Vestibular Activity and Cognitive Development in Children: Perspectives. Front. Integr. Neurosci. 2013, 7, 1-13. [CrossRef] [PubMed]

40. Pellis, S.M.; Pellis, V.C.; Bell, H.C. The Function of Play in the Development of the Social Brain. Am. J. Play. 2010, 2, 278-296.

41. Pellegrini, A.D.; Smith, P.K. Play and Development in Children. In International Encyclopedia of Social and Behavioral Sciences; Smelser, N.J., Bates, P., Eds.; Pergamon Press: Oxford, UK, 2001; pp. 11501-11503.

42. Nath, S.; Szücs, D. Construction Play and Cognitive Skills Associated with the Development of Mathematical Abilities in 7-Year-Old Children. Learn. Instr. 2014, 32, 73-80. [CrossRef]

43. Vygotsky, L.S. Mind in Society: The Development of Higher Psychological Processes; Harvard University Press: Cambridge, MA, USA, 1978.

44. Levine, Ratliff, C. Early Puzzle Play. Dev. Psychol. 2012, 48, 530-542. [CrossRef]

45. Pellegrini, A.D.; Gustafson, K. Boys' and Girls' Uses of Objects for Exploration, Play and Tools in Early Childhood. In The Nature of Play: Great Apes and Humans; Pellegrini, A.D., Smith, P.K., Eds.; Guilford Press: New York, NY, USA, 2005; pp. 113-138.

46. Lillard, A.S.; Lerner, M.D.; Hopkins, E.J.; Dore, R.A.; Smith, E.D.; Palmquist, C.M. The Impact of Pretend Play on Children's Development: A Review of the Evidence. Psychol. Bull. 2013, 139, 1-34. [CrossRef]

47. Christie, J.F.; Roskos, K.A. Standards, Science, and the Role of Play in Early Literacy Education. In Play=Learning: How Play Motivates and Enhances Cognitive and Social-Emotional Growth; Singer, D.G., Golinkoff, R.M., Hirsh-Pasek, K., Eds.; Oxford University Press: Oxford, UK, 2006; pp. 57-73.

48. Pellegrini, A.D. The Relationship between Kindergartners' Play and Achievement in Prereading, Language, and Writing. Psychol. Sch. 1980, 17, 530-535. [CrossRef]

49. Hoffmann, J.D.; Russ, S.W. Fostering Pretend Play Skills and Creativity in Elementary School Girls: A Group Play Intervention. Psychol. Aesthet. Creat. Arts 2016, 10, 114-125. [CrossRef]

50. Gilpin, A.T.; Brown, M.M.; Pierucci, J.M. Relations Between Fantasy Orientation and Emotion Regulation in Preschool. Early Educ. Dev. 2015, 26, 920-932. [CrossRef]

51. Nicolopoulou, A.; McDowell, J.; Brockmeyer, C. Narrative Play and Emergent Literacy: Storytelling and Story-Acting Meet Journal Writing. In Play=Learning: How Play Motivates and Enhances Cognitive and Social-Emotional Growth=Learning; Singer, D.G., Golinkoff, R.M., Hirsh-Pasek, K., Eds.; Oxford University Press: New York, NY, USA, 2006; pp. 124-144. [CrossRef]

52. Paley, V.G. A Child's Work: The Importance of Fantasy Play; Chicago University Press: Chicago, IL, USA, 2004. 
53. Isenberg, J.P.; Jalongo, M.R. Creative Expression and Play in Early Childhood, 4th ed.; Prentice Hall: Upper Saddle River, NJ, USA, 2006.

54. Kellert, S.R. Experiencing Nature: Affective, Cognitive, and Evaluative Development in Dhildren. In Children and Nature: Psychological, Sociocultural and Evolutionary Investigations; MIT Press: Cambridge, MA, USA, 2002; pp. 117-151.

55. Melson, G.F. Children and Wild Animals. In The Rediscovery of the Wild; Kahn, P., Hasbach, P.J., Eds.; The MIT Press: Cambridge, MA, USA, 2013; pp. 93-117.

56. Ballantyne, R.; Packer, J.; Sutherland, L.A. Visitors' Memories of Wildlife Tourism: Implications for the Design of Powerful Interpretive Experiences. Tour. Manag. 2011, 32, 770-779. [CrossRef]

57. Anderson, D.; Shimizu, H. Recollections of Expo 70: Visitors' Experiences and the Retention of Vivid Long-Term Memories. Curator Mus. J. 2007, 50, 435-454. [CrossRef]

58. Bixler, R.D.; Floyd, M.F.; Hammitt, W.E. Environmental Socialization: Quantitative Tests of the Childhood Play Hypothesis. Environ. Behav. 2002, 34, 795-818. [CrossRef]

59. Wells, N.M.; Lekies, K.S. Nature and the Life Course: Pathways from Childhood Nature Experiences to Adult Environmentalism. Youth Environ. 2006, 16, 1-24. [CrossRef]

60. Hedefalk, M.; Almqvist, J.; Östman, L. Education for Sustainable Development in Early Childhood Education: A Review of the Research Literature. Environ. Educ. Res. 2015, 21, 975-990. [CrossRef]

61. Kaplan, S. The Restorative Benefits of Nature. J. Environ. Psychol. 1995, 15, 169-182. [CrossRef]

62. Hart, R. Environmental Psychology or Behavioral Geography? Either Way, It Was a Good Start. J. Environ. Psychol. 1987, 7, 321-329. [CrossRef]

63. Sobel, D. Children's Special Places; Zephyr Press: Tuscon, AZ, USA, 1993.

64. Cooper Marcus, C. House as a Mirror of Self: Exploring the Deeper Meaning of Home; Conari Press: Berkeley, CA, USA, 1995.

65. Proshansky, H.M.M.; Fabian, A.K.K. The Development of Place Identity in the Child. In Spaces for Children: THE Built Environment and child Development; Weinstein, C.S., David, T.G., Eds.; Plenum Press: New York, NY, USA, 1987; pp. 21-40.

66. Hyndman, B.; Chancellor, B. Engaging Children in Activities beyond the Classroom Walls: A Social-Ecological Exploration of Australian Primary School Children's Enjoyment of School Play Activities. J. Play. Pract. 2015, 2, 117-141. [CrossRef]

67. Korpela, K.; Kyttä, M.; Hartig, T. Restorative Experience, Self-Regulation, and Children's Place Preferences. J. Environ. Psychol. 2002, 22, 387-398. [CrossRef]

68. Aminpour, F.; Bishop, K.; Corkery, L. The Hidden Value of In-between Spaces for Children's Self-Directed Play within Outdoor School Environments. Landsc. Urban Plan. 2020, 194, 103683. [CrossRef]

69. Coplan, R.J.; Rubin, K.H.; Fox, N.A.; Calkins, S.D.; Stewart, S.L.; Coplan, R.J.; Rubin, K.H.; Fox, N.A.; Calkins, S.D.; Stewart, S.L. Being Alone, Playing Alone, and Acting Alone: Distinguishing among Reticence and Passive and Active Solitude in Young Children. Child Dev. 1994, 65, 129-137. [CrossRef]

70. Marsh, J.; Bishop, J. Changing Play: Play, Media and Commercial Culture from the 1950s to the Present Date; Open University Press: Maidenhead, UK, 2014.

71. Marsh, J.; Plowman, L.; Yamada-Rice, D.; Bishop, J.; Scott, F. Digital Play: A New Classification. Early Years 2016, 36, 242-253. [CrossRef]

72. Cox, A.; Loebach, J.; Little, S. Understanding the Nature Play Milieu: Using Behavior Mapping to Investigate Children's Activities in Outdoor Play Spaces. Child. Youth Environ. 2018, 28, 232-261. [CrossRef]

73. Pellegrini, A.D. Kindergarten Children's Social Cognitive Status as a Predictor of First-Grade Success. Early Child. Res. Q. 1992, 7, 565-577. [CrossRef]

(C) 2020 by the authors. Licensee MDPI, Basel, Switzerland. This article is an open access article distributed under the terms and conditions of the Creative Commons Attribution (CC BY) license (http://creativecommons.org/licenses/by/4.0/). 